\title{
EDITORIAL
}

\section{PRIMACÍA DEL DERECHO DE LA UNIÓN EUROPEA Y SUS LÍMITES EN LA JURISPRUDENCIA RECIENTE DEL TJUE}

\author{
Prymacy of the EU law and its limits \\ in the recent case law of the CJEU \\ MANUEL LÓPEZ ESCUDERO ${ }^{1}$ \\ manlopez@ugr.es
}

Cómo citar/Citation

López Escudero, M. (2019).

Primacía del derecho de la Unión Europea y sus límites en la jurisprudencia reciente del TJUE. Revista de Derecho Comunitario Europeo, 64, 787-825. doi: https://doi.org/10.18042/cepc/rdce.64.01

\section{SUMARIO}

I. INTRODUCCIÓN. II. LA JURISPRUDENCIA CLÁSICA SOBRE LA PRIMACÍA: COSTA/ENEL, SIMMENTHAL Y SU AFINACIÓN POSTERIOR. III. LOS LÍMITES INTERNOS AL PRINCIPIO DE PRIMACÍA: 1. Ausencia de primacía de las normas de la Unión Europea sin efecto directo. 2. Limitación de la primacía por el principio de cosa juzgada. 3. Suspensión temporal de la primacía. IV. LOS LÍMITES EXTERNOS A LA PRIMACÍA DEL DERECHO DE LA UNIÓN EUROPEA Y SU RELACIÓN CON LAS CONSTITUCIONES NACIONALES. V. REFLEXIONES FINALES. BIBLIOGRAFÍA.

Director de la Revista de Derecho Comunitario Europeo, catedrático de Derecho Internacional Público y de Derecho de la UE de la Universidad de Granada y letrado del Tribunal de Justicia de la UE. Las reflexiones de este trabajo son estrictamente personales. 


\section{INTRODUCCIÓN}

La coexistencia en un mismo ámbito territorial del ordenamiento jurídico de la Unión Europea (UE) y del derecho interno de cada uno de los Estados miembros da lugar a la aparición de conflictos entre las normas de uno y otro ordenamiento. De acuerdo con la jurisprudencia clásica del Tribunal de Justicia de la Unión Europea (TJUE), estos conflictos han de resolverse mediante la aplicación del principio de la primacía del derecho de la UE sobre el derecho interno.

La construcción del principio de primacía la ha realizado el Tribunal de Justicia a golpe de sentencias, dado que los tratados constitutivos nunca la mencionaron $^{2}$. Esta labor del TJUE, crucial para la afirmación y supervivencia misma, diría yo, de la autoridad del derecho de la UE, ha estado siempre salpicada de problemas. Posiblemente, las dos dificultades principales a las que ha tenido que hacer frente el TJUE han sido, por un parte, la dificultad intrínseca para la determinación del alcance del principio de primacía y, por otra parte, la reticencia de algunas altas jurisdicciones nacionales, especialmente tribunales constitucionales, para aceptar la primacía del derecho de la

2 Para ser precisos, sí se alude a la primacía en la Declaración n. ${ }^{\circ} 17$ aneja al acta final de la Conferencia Intergubernamental (CIG) que adoptó el Tratado de Lisboa (DO 2010 C 83, p. 335), relativa a la primacía, en la que la CIG recuerda que, con arreglo a una jurisprudencia reiterada del Tribunal de Justicia, los Tratados y el derecho adoptado por la Unión sobre la base de los mismos priman sobre el derecho de los Estados miembros, en las condiciones establecidas por la citada jurisprudencia. Además, la CIG decidió incorporar al acta final el dictamen del Servicio Jurídico del Consejo, de 22 de junio de 2007, sobre la primacía, tal como figura en el documento 11197/07 (JUR 260), que afirma lo siguiente: «Resulta de la jurisprudencia del Tribunal de Justicia que la primacía del Derecho comunitario es un principio fundamental del Derecho comunitario. Según el Tribunal de Justicia, este principio es inherente a la naturaleza específica de la Comunidad Europea. En el momento de la primera sentencia de esta jurisprudencia constante (Costa/ENEL, de 15 de julio de 1964, asunto 6/64) el Tratado no contenía mención alguna a la primacía, y todavía hoy sigue sin contenerla. El hecho de que el principio de primacía no esté incluido en el futuro Tratado no cambiará en modo alguno la existencia de este principio ni la jurisprudencia existente del Tribunal de Justicia».

No obstante, el Tratado de Lisboa no rescató la consagración expresa del principio de primacía, contenida en el tratado por el que se establece una constitución para Europa, firmado en Roma el 29 de octubre de 2004 (DO 2004 C 310, p. 1), que proclamó explícitamente en su art. I-6 la primacía del derecho originario y derivado sobre los derechos internos de los Estados en el ámbito de las competencias atribuidas a la UE. 
UE sobre las disposiciones de las constituciones nacionales. Ambas dificultades han dado lugar, respectivamente, a la aparición de límites internos y de limitaciones externas al principio de primacía.

La jurisprudencia reciente del Tribunal de Justicia nos está ofreciendo una rica casuística sobre estas dos dificultades y los límites que generan para la operatividad del principio de primacía. El presente editorial pretender llevar a cabo una reflexión al respecto, no sin antes recordar la jurisprudencia clásica iniciada hace ya casi setenta años por el Tribunal de Justicia con su emblemática sentencia Costa/ENEL y perfilada, también, en los últimos tiempos por el Tribunal.

\section{LA JURISPRUDENCIA CLÁSICA SOBRE LA PRIMACÍA: COSTA/ENEL, SIMMENTHAL Y SU AFINACIÓN POSTERIOR}

El principio de primacía es una sólida construcción jurisprudencial del Tribunal de Justicia que tuvo su arranque en la sentencia Costa/Enel en $1964^{3}$ y que se perfiló con la sentencia Simmenthal de 19784. En el primero de dichos asuntos, un abogado de Milán, Flaminio Costa, impugnó el recibo de la luz al estimar que era contraria al derecho de la Unión la ley italiana de 6 de diciembre de 1962, que nacionalizaba la producción y distribución de la energía eléctrica. Como se trataba de una ley posterior a la que había incorporado el Tratado constitutivo de la Comunidad al ordenamiento italiano, el juez nacional que conoció el litigio promovió una cuestión de inconstitucionalidad en relación con dicha ley y simultáneamente planteó una cuestión prejudicial de interpretación al Tribunal de Justicia. El 7 de marzo de 1964, el Tribunal Constitucional italiano resolvió la cuestión de inconstitucionalidad con los criterios propios de un sistema dualista como el italiano y determinó que el juez nacional estaba obligado a aplicar la ley interna posterior.

En su sentencia Costa/Enel, el Tribunal de Justicia reaccionó ante esta solución y sentó el principio de primacía de la norma de la Unión sobre la nacional, tras afirmar que el régimen de aplicación de las normas de la UE en los ordenamientos nacionales de los Estados miembros viene determinado por el propio derecho de la Unión. La argumentación de la sentencia Costa/Enel fue particularmente esclarecedora y merece ser recordada.

En primer lugar, a diferencia de los tratados internacionales ordinarios, el TCEE creó un ordenamiento jurídico propio, integrado en el sistema ju-

\footnotetext{
3 Sentencia de 15 de julio de 1964, Costa, 6/64, EU:C:1964:66.

4 Sentencia de 9 de marzo de 1978, Simmenthal, 106/77, EU:C:1978:49.
} 
rídico de los Estados miembros desde la entrada en vigor de dicho tratado, y que vincula a sus órganos jurisdiccionales. Este ordenamiento pertenece a una Comunidad de duración indefinida, dotada de instituciones propias, de personalidad, de capacidad jurídica, de capacidad de representación internacional y, más en particular, de poderes reales derivados de una limitación de competencia o de una transferencia de atribuciones de los Estados a la Comunidad, en virtud de las cuales estos han limitado su soberanía, aunque en materias específicas, y han creado así un cuerpo normativo aplicable a sus nacionales y a sí mismos.

En segundo lugar, la integración en el derecho de cada país miembro de disposiciones procedentes de fuentes comunitarias, y más en general los términos y el espíritu del tratado, tiene como corolario la imposibilidad de que los Estados hagan prevalecer, contra un ordenamiento jurídico por ellos aceptado sobre una base de reciprocidad, una medida unilateral posterior, que no puede por tanto oponerse a dicho ordenamiento. Subraya el Tribunal de Justicia que la fuerza vinculante del derecho de la Unión no puede variar de un Estado miembro a otro, en razón de legislaciones internas ulteriores, sin que se ponga en peligro la realización de los objetivos del tratado, y añade que las obligaciones contraídas mediante el Tratado constitutivo de la Comunidad no serían incondicionales, sino solamente eventuales, si pudieran quedar cuestionadas por los actos legislativos futuros de los Estados miembros.

En tercer lugar, la primacía del derecho comunitario está confirmada por el art. 189 TCEE, a cuyo tenor los reglamentos tienen fuerza «obligatoria» y son «directamente aplicables en cada Estado miembro», ya que esta disposición, que no está acompañada de reserva alguna, carecería de alcance si un Estado miembro pudiera unilateralmente destruir sus efectos mediante un acto legislativo oponible a las normas comunitarias.

Estos razonamientos llevaron al Tribunal de Justicia a concluir que «al Derecho creado por el Tratado, nacido de una fuente autónoma, no se puede oponer, en razón de su específica naturaleza original una norma interna, cualquiera que sea ésta, ante los órganos jurisdiccionales, sin que al mismo tiempo aquél pierda su carácter comunitario y se ponga en tela de juicio la base jurídica misma de la Comunidad» y que «la transferencia realizada por los Estados, de su ordenamiento jurídico interno en favor del comunitario, de los derechos y obligaciones correspondientes a las disposiciones del Tratado, entraña por tanto una limitación definitiva de su soberanía, contra la que no puede prevalecer un acto unilateral ulterior incompatible con el concepto de Comunidad».

Como puede apreciarse, en la sentencia Costa/Enel el TJUE construye el principio de primacía, al igual que hizo con el efecto directo, sobre la base del propio derecho de la UE. De esta manera, las relaciones entre los 
derechos internos y el derecho de la UE quedan articuladas de conformidad con estos principios que forman parte del derecho de la Unión, siendo comunes e iguales para todos los Estados miembros. Así, queda excluida y desterrada la aplicación a las normas de la UE de las normas constitucionales nacionales sobre la incorporación de normas internacionales en los derechos internos.

Las consecuencias del principio de primacía para la actuación de los jueces nacionales fueron precisadas por el Tribunal de Justicia en su sentencia Simmenthal, en la que concluyó que «el juez nacional encargado de aplicar, en el marco de su competencia, las disposiciones del Derecho comunitario, está obligado a garantizar la plena eficacia de dichas normas dejando, si procede, inaplicadas, por su propia iniciativa, cualesquiera disposiciones contrarias de la legislación nacional, aunque sean posteriores, sin que esté obligado a solicitar o a esperar la derogación previa de éstas por vía legislativa o por cualquier otro procedimiento constitucional» ${ }^{5}$. La primacía conlleva, por tanto, para el juez nacional la obligación de dejar inaplicada la norma nacional contraria al derecho de la UE y de resolver el litigio que tiene pendiente utilizando la norma de la UE.

En un obiter dicta de esta sentencia Simmenthal, el TJUE fue más allá y dijo que

en virtud del principio de la primacía del derecho comunitario, las disposiciones del Tratado y los actos de las instituciones directamente aplicables tienen por efecto, en sus relaciones con el Derecho interno de los Estados miembros, no solamente hacer inaplicable de pleno derecho, por el propio hecho de su entrada en vigor, a cualquier disposición contraria de la legislación nacional existente, sino además $[. .$.$] impedir la formación válida de nuevos actos incompatibles con$ normas comunitarias ${ }^{6}$.

Estas afirmaciones obedecieron a las circunstancias concretas del caso y no deben ser consideradas como expresión de un principio general. La significación fundamental de esta sentencia radica en la afirmación de la obligación del juez nacional, en el ámbito de su competencia, de garantizar la plena eficacia de la norma de la UE y, por consiguiente, de dejar, en su caso, inaplicada la ley nacional contraria, con independencia de que esta sea anterior o posterior y de que la facultad de inaplicar las leyes le sea reconocida o no por su sistema constitucional.

5 Sentencia de 9 de marzo de 1978, Simmenthal, 106/77, EU:C:1978:49, apdo. 24.

6 Ibid., apdo. 21. 
El TJUE confirmó esta interpretación en sus sentencias INCOGE y Filipiak, en las que afirmó que de la sentencia Simmenthal

no puede deducirse que la incompatibilidad con el Derecho comunitario de una norma nacional posterior produzca el efecto de determinar la inexistencia de ésta. Ante semejante situación, el juez nacional está obligado, en cambio, a descartar la aplicación de esa norma en la inteligencia de que esta obligación no limita la facultad de los órganos jurisdiccionales nacionales competentes para aplicar, entre los distintos procedimientos del ordenamiento jurídico interno, aquéllos que sean apropiados para salvaguardar los derechos individuales reconocidos por el Derecho comunitario.

\section{El Tribunal de Justicia reiteró que}

en virtud del principio de primacía del Derecho comunitario, el juez nacional debe resolver sobre el conflicto entre una disposición de Derecho nacional y otra del Tratado directamente aplicable mediante la aplicación del Derecho comunitario, dejando inaplicada cualquier disposición contraria de la legislación nacional, y no mediante la declaración de nulidad de la disposición nacional contraria, ya que corresponde a cada Estado miembro determinar las competencias de sus tribunales en este sentido ${ }^{7}$.

La obligación de garantizar la primacía de las normas de la UE no es una tarea exclusiva de los jueces nacionales, sino que se aplica también a todas las autoridades de los Estados miembros. El principio de primacía consagra la preeminencia del derecho de la Unión sobre los derechos internos y, por consiguiente, impone la obligación de garantizar la plena eficacia de las distintas normas de la Unión a todos los órganos e instituciones de los Estados miembros, sin que su derecho interno pueda afectar a la eficacia reconocida a esas distintas normas en el territorio de dichos Estados ${ }^{8}$. En concreto, ha precisado el TJUE que el deber de excluir la aplicación de una normativa nacional contraria al derecho de la Unión no solamente incumbe a los jueces y tribunales nacionales, sino también a todos los órganos del Estado -incluidas las auto-

7 Sentencias de 22 de octubre de 1998, INCOGE y otros, C-10/97 a C-22/97, EU:C:1998:498, apdo. 21, y de 19 de noviembre de 2009, Filipiak, C314/08, EU:C:2009:719, apdos. 82 y 83.

8 Sentencias de 26 de febrero de 2013, Melloni, C-399/11, EU:C:2013:107, apdo. 59; de 4 de diciembre de 2018, Minister for Justice and Equality y Commissioner of An Garda Síochána, C-378/17, EU:C:2018:979, apdo. 39, y de 24 de junio de 2019, Poplawski, C-573/17, EU:C:2019:530, apdos. 53 y 54. 
ridades administrativas - encargados de aplicar, en el marco de sus respectivas competencias, el derecho de la Unión?.

En sus sentencias más recientes, el Tribunal de Justicia ha perfilado más el principio de primacía y la obligación que de él se deriva para el juez nacional de dejar inaplicadas las normas internas contrarias al derecho de la Unión. Así, afirma que el órgano jurisdiccional nacional encargado de aplicar, en el ámbito de su competencia, las disposiciones del derecho de la Unión está obligado a garantizar la plena eficacia de estas disposiciones dejando inaplicada de oficio, en caso de necesidad, cualquier disposición nacional contraria sin solicitar o esperar la derogación previa de dicha disposición nacional por el legislador o mediante cualquier otro procedimiento constitucional ${ }^{10}$. Para permitir que el juez nacional pueda actuar con toda intensidad a la hora de hacer desplegar sus efectos al principio de primacía, el TJUE reitera que es incompatible con las exigencias inherentes a la propia naturaleza del derecho de la Unión toda disposición de un ordenamiento jurídico nacional o cualesquiera prácticas, legislativas, administrativas o judiciales, que tengan por efecto disminuir la eficacia del derecho de la Unión por el hecho de negar al juez competente para aplicar este derecho la facultad de hacer, en el momento mismo de dicha aplicación, cuanto sea necesario para descartar las disposiciones legales nacionales que, en su caso, constituyan un obstáculo a la plena eficacia de las normas del derecho de la Unión directamente aplicables ${ }^{11}$.

9 Véanse, en este sentido, las sentencias de 22 de junio de 1989, Costanzo, 103/88, EU:C:1989:256, apartado 31; de 9 de septiembre de 2003, CIF, C 198/01, EU:C:2003:430, apdo. 49; de 12 de enero de 2010, Petersen, C-341/08, EU:C:2010:4, apdo. 80; de 14 de septiembre de 2017, The Trustees of the BT Pension Scheme, C-628/15, EU:C:2017:687, apdo. 54, y de 4 de diciembre de 2018, Minister for Justice and Equality y Commissioner of An Garda Síochána, C-378/17, EU:C:2018:979, apdos. 38 y 39.

Sentencias de 20 de octubre de 2011, Interedil, C396/09, EU:C:2011:671, apdo. 38; de 4 de junio de 2015, Kernkraftwerke Lippe-Ems, C-5/14, EU:C:2015:354, apdo. 32; de 5 de abril de 2016, PFE, C-689/13, EU:C:2016:199, apartado 40; de 5 de julio de 2016, Ognyanov, C-614/14, EU:C:2016:514, apdo. 34; de 4 de diciembre de 2018, Minister for Justice and Equality y Commissioner of An Garda Síochána, C-378/17, EU:C:2018:979, apdo. 35; de 6 de marzo de 2018, SEGRO y Horváth, C-52/16 y C-113/16, EU:C:2018:157, apdo. 46, y de 24 de junio de 2019, Poplawski, C-573/17, EU:C:2019:530, apdo. 58.

11 Sentencias 19 de junio de 1990, Factortame y otros, C-213/89, EU:C:1990:257, apdo. 20; de 8 de septiembre de 2010, Winner Wetten, C-409/06, EU:C:2010:503, apdo. 56; de 26 de febrero de 2013, Åkerberg Fransson, C-617/10, EU:C:2013:280, apdos. 45 y 46, y de 4 de diciembre de 2018, Minister for Justice and Equality y Commissioner of An Garda Síochána, C-378/17, EU:C:2018:979, apdo. 36. 
A estos efectos, los órganos jurisdiccionales nacionales pueden aplicar, de entre los distintos procedimientos del ordenamiento jurídico interno, aquellos que sean apropiados para salvaguardar los derechos individuales reconocidos por el derecho de la Unión ${ }^{12}$.

Ello ha llevado al TJUE a considerar que serían contrarias al derecho de la UE aquellas normas procesales nacionales que obliguen a un tribunal inferior a resolver un asunto aplicando una decisión de un tribunal superior vinculante para él cuando no sea conforme al derecho de la UE, disponiendo siempre el juez inferior de la posibilidad de plantear una cuestión prejudicial al Tribunal de Justicia ${ }^{13}$. De la misma manera, la aplicación del principio de primacía lleva a descartar la aplicación de una norma nacional que imponga a una sala de un órgano jurisdiccional de última instancia, que no comparte la orientación marcada por una resolución del pleno de ese órgano jurisdiccional, la obligación de remitir la cuestión al mencionado pleno y le impide, por tanto, plantear una petición de decisión prejudicial ante el Tribunal de Justicia ${ }^{14}$.

La obligación que la primacía impone a los jueces nacionales para garantizar la plena eficacia del derecho de la Unión incluye, como es lógico, el deber de modificar, en caso necesario, su jurisprudencia reiterada si esta se basa en una interpretación del derecho interno incompatible con el derecho de la Unión ${ }^{15}$.

Aparte de obligar a los jueces nacionales a dejar inaplicadas las normas internas contrarias al derecho de la Unión, el principio de primacía conlleva la obligación de los Estados miembros de derogar o modificar las disposiciones de su derecho interno que sean incompatibles con las normas de derecho de la Unión. No basta con que los jueces nacionales inapliquen una norma nacional contraria al derecho de la Unión; la seguridad jurídica requiere que dicha norma sea eliminada del ordenamiento jurídico interno para evitar ambigüedades que dificulten la aplicación de las normas de la Unión ${ }^{16}$. Si el Estado miembro es renuente a la eliminación o modificación de la norma interna, la Comisión cuenta con la posibilidad de abrir un recurso de incumplimiento contra dicho Estado.

12 Sentencias de22 deoctubre de 1998, INCOGEyotros, C-10/97 aC-22/97,EU:C:1998: 498, apdo. 21, y de 19 de julio de 2012, Littlewoods Retail y otros, C-591/10, EU:C:2012:478, apdo. 33.

13 Sentencias de 9 de marzo de 2010, ERG y otros, C-378/08, EU:C:2010:126, apdo. 32, y de 5 de octubre de 2010, Elchinov, C-173/09, EU:C:2010:581, apdo. 27.

14 Sentencia de 5 de abril de 2016, PFE, C-689/13, EU:C:2016:199, apdo. 38.

15 Ver, en este sentido, la sentencia de 19 de abril de 2016, DI, C-441/14, EU:C:2016:278, apdo. 33 y jurisprudencia citada.

16 Sentencia de 4 de abril de 1974, Comisión/Francia, 167/73, EU:C:1974:35, apdo. 41. 


\section{LOS LÍMITES INTERNOS AL PRINCIPIO DE PRIMACÍA}

La jurisprudencia del TJUE que acabamos de exponer confiere a la aplicación del principio de primacía dos efectos ${ }^{17}$ que nos interesa distinguir para analizar algunos pronunciamientos recientes del Tribunal de Justicia. Por una parte, la primacía conlleva el efecto de exclusión, según el cual la norma de la UE impide la aplicación de la norma nacional de contenido contrario. Por otra parte, el principio de primacía puede conllevar el efecto de sustitución, que supone que la norma de la UE se aplica a la relación jurídica y se descarta la aplicación de la norma interna de contenido contrario. ${ }^{18}$

El efecto de exclusión de la primacía, es decir, la neutralización de la norma nacional contraria al derecho de la UE, opera (o debería operar) en todos los casos de conflicto normativo entre el derecho UE y el derecho interno de un Estado miembro. Este efecto de exclusión de la primacía no es dependiente de la aptitud para producir efecto directo de la norma de la UE en cuestión. Por ello, la exclusión de la norma interna viene impuesta por el principio de primacía cuando la norma de la UE puede ser invocada directamente por un particular ante los jueces o la administración nacional. Pero también se producirá el efecto de exclusión de la primacía en los casos de conflictos normativos abstractos (desconectados de un litigio individual) entre una norma de la Unión y normas nacionales. La vía procesal típica que permite la operatividad de este efecto del principio de primacía es el recurso de incumplimiento (arts. 258-260 TFUE), mediante el cual el TJUE puede declarar que un Estado miembro incumple el derecho de la UE con la adopción o la no eliminación de una norma interna y puede, además, imponer una sanción pecuniaria al Estado infractor en caso de continuación de su infracción. Aquí, el principio de primacía supone un mandato de exclusión de la aplicación de la norma interna y de su depuración para las autoridades del Estado miembro, que deben eliminar de su derecho interno las normas nacionales generadoras del incumplimiento.

El efecto de sustitución del principio de primacía se traduce en el mandato para el juez nacional (también para la Administración) de inaplicar la norma nacional contraria al derecho de la UE en el litigio del que está cono-

17 La doctrina ha diferenciado tres tipos de efectos o de maneras de invocación de las directivas de la UE, a saber, la invocabilidad de sustitución, la invocabilidad de exclusión, la invocabilidad de interpretación y la invocabilidad de reparación. Véanse, entre otros, los trabajos de Simon (1997) y Dubos (2003).

18 Para explicar las consecuencias del principio de primacía es posible, también, distinguir entre la vertiente normativa y la vertiente aplicativa de la primacía, como hace Sarmiento (2018a: 328). 
ciendo y de resolverlo aplicando la norma de la UE. Este efecto de sustitución, que incluye al de exclusión, está estrechamente vinculado con el efecto directo, ya que la norma de la UE solo desplazará a la norma nacional contraria y se aplicará para resolver el litigio si el particular la puede invocar ante los jueces nacionales por cumplir las condiciones para producir efecto directo.

Este efecto de sustitución de la primacía es el que ha dado lugar a más jurisprudencia del TJUE y es, también, donde se aprecian desarrollos recientes de gran interés, que ponen de manifiesto que el principio de primacía incondicional y absoluta, establecido por el TJUE, no siempre puede ser aplicado por los jueces nacionales con toda su intensidad. Dicho en otros términos, el TJUE ha tenido que admitir «limitaciones internas», establecidas en su propia jurisprudencia, a la aplicación de la primacía por parte de los jueces nacionales ${ }^{19}$.

Analizaré como botón de muestra de estas limitaciones internas a la primacía tres supuestos de la jurisprudencia del TJUE especialmente ilustrativos: la ausencia de primacía de las normas de la UE carentes de efecto directo, la limitación de la primacía por el principio de cosa juzgada y la suspensión temporal de la primacía.

\section{AUSENCIA DE PRIMACÍA DE LAS NORMAS DE LA UNIÓN EUROPEA SIN EFECTO DIRECTO}

La jurisprudencia reciente del TJUE sobre la relación entre primacía y efecto directo es sumamente rica y «conflictiva». La cuestión fundamental que me interesa destacar es si el efecto directo es una conditio sine qua non para que una norma de la UE despliegue los efectos de exclusión y de sustitución de la primacía en relación con una norma nacional contraria. Las sentencias más recientes sobre directivas y decisiones marco parecen inclinarse, salvo alguna excepción y opiniones contrarias de abogados generales, por hacer depender los dos efectos del principio de la primacía del requisito de que la norma de la UE pueda desplegar efecto directo en el litigio principal, es decir, que pueda ser invocada directamente por el particular. Esta condición me parece aceptable respecto al efecto de sustitución, pero la considero criticable en relación con el efecto de exclusión de la primacía.

Con la sentencia Pfeiffer, el TJUE optó implícitamente por privilegiar la interpretación del derecho nacional conforme a las disposiciones de las directivas, en detrimento de la afirmación del efecto de exclusión de dichas normas

19 Esta terminología de límites internos (limiti interni) a la primacía es utilizada, por ejemplo, por Arena (2019: 331). 
de la UE respecto al derecho nacional contrario, como sugería el abogado general Dámaso Ruiz-Jarabo Colomer ${ }^{20}$. Esta opción del TJUE se verbalizó en la sentencia Fenoll, al afirmar que, de no ser posible una interpretación del derecho nacional conforme al art. 7 de la Directiva 2003/88, que prevé el derecho a vacaciones anuales retribuidas, este precepto «no puede ser invocado en un litigio entre particulares como el asunto principal para garantizar el pleno efecto del derecho a vacaciones anuales retribuidas y dejar inaplicada toda disposición nacional contraria $»^{21}$.

Con posterioridad, la sentencia Smith afirma que

un órgano jurisdiccional nacional que conoce de un litigio entre particulares, que se encuentra en la imposibilidad de dar a las disposiciones de su derecho nacional una interpretación conforme con una directiva, no está obligado, basándose únicamente en el derecho de la Unión, a inaplicar las disposiciones de su legislación nacional contrarias a las disposiciones de dicha directiva que cumplen todos los requisitos exigidos para producir efecto directo y a ampliar así la posibilidad de invocar una disposición de una directiva no transpuesta, o transpuesta de manera incorrecta, al ámbito de las relaciones entre los particulares ${ }^{22}$.

En este caso, el art. 1 de la Directiva 90/232/CEE del Consejo, de 14 de mayo de 1990, tercera directiva relativa a la aproximación de las legislaciones de los Estados miembros sobre el seguro de responsabilidad civil derivada de la circulación de vehículos automóviles, cumplía las condiciones para desplegar efecto directo, pero su primacía sobre las normas irlandesas y una cláusula contractual basada en ellas, de contenido contrario, no permitía al juez irlandés inaplicar estas últimas y resolver el litigio de acuerdo con la directiva por tratarse de una relación horizontal (indemnización de los daños sufridos por el Sr. Smith a raíz de un accidente de circulación en el que estuvo implicado un vehículo conducido por el Sr. Patrick Meade, propiedad del Sr. Philip Meade y asegurado por FBD).

Como puede apreciarse, el rechazo del efecto directo horizontal de las directivas impide que la primacía despliegue su efecto de sustitución de la norma nacional contraria, incluso cuando el precepto de la directiva cumple las condiciones para desplegar efecto directo. Para paliar este resultado, el TJUE incita al juez nacional a exprimir al máximo el principio de interpretación

20 Sentencia de 5 de octubre de 2004, Pfeiffer y otros, C-397/01 a C-403/01, EU:C:2004: 584, y conclusiones de 6 de mayo de 2003, Pfeiffer y otros, C-397/01 a C-403/01, EU:C:2003:245, punto 58.

21 Sentencia de 26 de marzo de 2015, Fenoll, C-316/13, EU:C:2015:200, apdo. 48.

22 Sentencia de 7 de agosto de 2018, Smith, C-122/17, EU:C:2018631, apdo. 49. 
conforme con el derecho de la UE de las normas nacionales, pero si dicha interpretación no resulta factible, la única vía que le queda al particular perjudicado por la falta de conformidad del derecho nacional con el derecho de la Unión es invocar la jurisprudencia Francovich y otros para obtener del Estado miembro, en su caso, la reparación del perjuicio sufrido ${ }^{23}$.

Sin embargo, el TJUE sí aceptó en la sentencia Link Logistik ${ }^{24}$ que una disposición de una directiva carente de la aptitud para desplegar efecto directo fuese invocada por un particular en una relación vertical contra la administración húngara para impedir la aplicación de la normativa nacional incompatible con la directiva. En este caso, que constituye un precedente aislado, el TJUE no hace depender los efectos de la primacía del posible efecto directo de la norma de la UE.

La negación de los efectos de exclusión y de sustitución de la primacía respecto a normas nacionales contrarias a directivas invocadas entre particulares en relaciones jurídicas horizontales me parece criticable y es un resultado muy poco conveniente para conseguir una aplicación efectiva y uniforme de las directivas de la UE.

Posiblemente, esta circunstancia explica el desarrollo jurisprudencial, apuntado con las sentencias Mangold y Kücükdeveci, y que se ha afirmado recientemente con las sentencias Engerberg, Bauer y Willmeroth, IR, y Cresco Investigation, entre otras ${ }^{25}$. En ellas, el TJUE admite que el efecto de exclusión de la primacía opere respecto a un precepto de una directiva en una relación jurídica horizontal, siempre que dicha norma suponga la concreción de un principio general del derecho de la Unión o de un derecho fundamental consagrado en la Carta de Derechos Fundamentales de la UE (CDFUE, en adelante) —Wildemeersch, (2018: 546-552) —. En estos casos, los efectos de la directiva no operan en las relaciones horizontales entre particulares, pero las disposiciones de la CDFUE que expresan el contenido de la directiva sí que disfrutan de efecto directo horizontal y su primacía puede desplegar el efecto de exclusión y el efecto de sustitución respecto a las normas nacionales contrarias.

23 Sentencias de 19 de abril de 2007, Farrell, C-356/05, EU:C:2007:229, apdo. 43; de 24 de enero de 2012, Domínguez, C-282/10, EU:C:2012:33, apdo. 43, y de 7 de agosto de 2018, Smith, C-122/17, EU:C:2018631, apdo. 56.

24 Sentencia de 4 de octubre de 2018, Link Logistik N\&N, C-384/17, EU:C:2018:810, apdos. 60-62.

25 Sentencias de 17 de abril de 2018, Egenberger, C-414/16, EU:C:2018:257; de 11 de septiembre de 2018, IR, C-68/17, EU:C:2018:696; de 6 de noviembre de 2018, Bauer y Willmeroth, C-569/16 y C-70/16, EU:C:2018:871, y de 22 de noviembre de 2019, Cresco Investigation, C-193/17, EU:C:2019:43. 
Un ejemplo particularmente clarificador de esta jurisprudencia lo ofrecen los asuntos Bauer y Willmeroth. La Sra. Bauer era la heredera de un trabajador del Ayuntamiento Wuppertal, que había fallecido sin cobrar todos sus días de vacaciones (relación vertical) y el Sr. Willmeroth era un empresario alemán que negó a la viuda de uno de sus empleados el abono de las vacaciones no cobradas tras el fallecimiento de este (relación horizontal). Según el TJUE, cuando la relación laboral concluye por fallecimiento del trabajador, tanto del art. 7, apdo. 2, de la Directiva 2003/88 como del art. 31, apdo. 2, de la Carta se infiere que, para evitar la pérdida retroactiva del derecho fundamental a vacaciones anuales retribuidas adquirido por ese trabajador, incluida su vertiente patrimonial, el derecho del interesado a una compensación económica por las vacaciones no disfrutadas es transmisible mortis causa a sus herederos. La normativa alemana aplicable a ambos asuntos impedía dicha transmisión mortis causa en violación de las normas de la UE y no era factible aplicarle el criterio de la interpretación conforme al derecho de la UE.

Para hacer jugar los efectos del principio de primacía, el TJUE consideró suficiente la invocación directa del art. 7 de la Directiva 2003/88, cuyos apdos. 1 y 2 cumplían las condiciones para desplegar efecto directo, en el caso de la relación vertical entre la Sra. Bauer y el Ayuntamiento de Wuppertal ${ }^{26}$. Sin embargo, en la relación horizontal entre el Sr. Willmeroth y la heredera de su empleado fallecido, la primacía del art. 7 de la Directiva 2003/88 no podía desplegar sus efectos porque dicho precepto «no podía ser invocado en un litigio entre particulares para garantizar el pleno efecto del derecho a vacaciones anuales retribuidas y dejar inaplicada toda disposición nacional contraria $»^{27}$. Por ello, el TJUE acude al art. 31, apdo. 2, de la Carta, determinando que recoge un principio fundamental del derecho social de la Unión, de aplicación directa, y concluye que el juez nacional debe abstenerse de aplicar una normativa nacional, como la controvertida en los litigios principales, con arreglo a la cual el fallecimiento del trabajador determina, con efectos retroactivos, la extinción de los derechos relativos a las vacaciones anuales retribuidas que adquirió con anterioridad a su deceso y, consecuentemente, la imposibilidad de que sus herederos perciban la compensación económica sustitutoria, como

26 Sentencias de 6 de noviembre de 2018, Bauer y Willmeroth, C-569/16 y C-70/16, EU:C:2018:871, apdos. 72 y 73; de 24 de enero de 2012, Domínguez, C-282/10, EU:C: 2012:33, apdos. 34 a 36, y de 12 de junio de 2014, Bollacke, C-118/13, EU:C:2014: 1755 , apdo. 28.

27 Sentencias de 26 de marzo de 2015, Fenoll, C-316/13, EU:C:2015:200, apdo. 48; de 7 de agosto de 2018, Smith, C-122/17, EU:C:2018:631, apdo. 43, y de 6 de noviembre de 2018, Bauer y Willmeroth, C-569/16 y C-70/16, EU:C:2018:871, apdos. 77 y 78 . 
vertiente patrimonial constitutiva de esos derechos, y, por otro lado, que los empresarios no pueden invocar la existencia de tal normativa nacional con el fin de eludir el pago de la referida compensación económica al que están obligados para respetar el derecho fundamental garantizado por dicha disposición $^{28}$.

La sentencia Cresco Investigation ofrece también otro ejemplo interesante de esta evolución jurisprudencial. En este caso, el Sr. Achatzi era un trabajador por cuenta ajena de la empresa Cresco, agencia de detectives privados, pero no era miembro de ninguna de las iglesias contempladas en la ley austriaca sobre el descanso laboral y, por ello, no tenía derecho a disfrutar el Viernes Santo como día festivo. El Sr. Achatzi consideró discriminatoria la decisión de no abonarle el complemento por trabajo en día festivo por el trabajo que desempeñó el 3 de abril de 2015, día de Viernes Santo, y reclamó a su empleador, por este concepto, el pago de 109,09 euros más los intereses correspondientes. Al permitir solo a los trabajadores afiliados formalmente a determinadas iglesias disfrutar del Viernes Santo como día de descanso o cobrar un complemento laboral en caso de trabajar ese día, la legislación austriaca producía el efecto de tratar de diferente manera, en función de la religión, unas situaciones análogas. Por ello, el TJUE consideró que establecía una discriminación directa por motivos de religión, en el sentido del art. 2, apdo. 2, letra a), de la Directiva 2000/78 carente de justificación ${ }^{29}$.

Como se trataba de una relación jurídica entre particulares, la primacía del art. 2 de la Directiva 2000/78 no podía desplegar sus efectos porque no admite el TJUE el efecto directo horizontal de las directivas. La interpretación de la legislación austríaca conforme a dicha directiva tampoco era posible. Entonces, lo que hizo el Tribunal fue recurrir al art. 21, apdo. 1, de la CDFUE, considerar que este precepto recoge la prohibición de toda discriminación basada en la religión o las convicciones con carácter imperativo como principio general del derecho de la Unión y afirmar que, establecida en el art. 21, apdo. 1 , de la Carta, dicha prohibición es suficiente por sí sola para conferir a los particulares un derecho invocable como tal en un litigio que les enfrente en un ámbito regulado por el derecho de la Unión. ${ }^{30}$ Aplicando el art. 21 de la

28 Sentencia de 6 de noviembre de 2018, Bauer y Willmeroth, C-569/16 y C-70/16, EU:C:2018:871, apdo. 86.

29 Sentencia de 22 de noviembre de 2019, Cresco Investigation, C-193/17, EU:C:2019: 43, apdo. 69.

30 Ibid., apdos. 76 y 77. Este razonamiento lo había utilizado ya el TJUE en la Sentencia de 17 de abril de 2018, Egenberger, C-414/16, EU:C:2018:257, apdo. 76. 
CDFUE, conectado con la Directiva 2000/78, la primacía del derecho de la UE despliega sus efectos de exclusión y de sustitución.

En este caso, el efecto de exclusión de la primacía impide la aplicación de la normativa austriaca discriminatoria, pero el efecto de sustitución no llevó a la solución del litigio principal mediante la aplicación del art. 21 CDFUE y de la Directiva 2000/78. Para dar efecto a la primacía, el juez nacional tuvo que aplicar al Sr. Achatzi la normativa interna más favorable ${ }^{31}$ y reconocer su derecho a cobrar el complemento por trabajar el Viernes Santo y la consiguiente obligación del empleador de pagárselo.

Al igual que en el caso de la aplicación de las directivas en relaciones horizontales, la primacía del derecho de la Unión presenta problemas para desplegar sus efectos en los supuestos de aplicación de las decisiones marco, que son actos normativos de la UE adoptados sobre la base del antiguo tercer pilar de la Unión, concretamente, con arreglo al art. 34 UE, apdo. 2, letra b). Esta norma establecía, por una parte, que las decisiones marco obligan a los Estados miembros en cuanto al resultado que deba conseguirse, dejando, sin embargo, a las autoridades nacionales la elección de la forma $\mathrm{y}$ de los medios y, por otra parte, que las decisiones marco no pueden tener efecto directo.

La sentencia Poplawski I ${ }^{32}$ es particularmente ilustrativa de estas dificultades de la primacía para desplegar sus efectos en relación con las decisiones marco. La cuestión prejudicial se presentó en el contexto de la ejecución en los Países Bajos de una orden de detención europea (en lo sucesivo, ODE) dictada por el Tribunal de Distrito de Poznan, Polonia, contra el Sr. Popławski, a efectos de la ejecución en Polonia de una pena privativa de libertad. El tribunal neerlandés remitente preguntaba, en esencia, si el principio de primacía del derecho de la Unión debe interpretarse en el sentido de que obliga al órgano jurisdiccional de un Estado miembro a abstenerse de aplicar una disposición del derecho de ese Estado incompatible con determinadas dispo-

31 El TJUE afirmó que «el juez nacional debe dejar sin aplicar toda disposición nacional discriminatoria, sin solicitar o esperar su previa derogación por el legislador, y debe aplicar a los miembros del grupo desfavorecido el mismo régimen que aquel del que disfrutan las personas de la otra categoría. Está obligado a ello con independencia de que en el Derecho interno existan o no disposiciones que le confieran la competencia para hacerlo» (sentencias de 9 de marzo de 2017, Milkova, C-406/15, EU:C:2017:198, apdo. 67, y de 22 de noviembre de 2019, Cresco Investigation, C-193/17, EU:C:2019:43, apdos. 79-81).

32 Sentencia de 24 de junio de 2019, Poplawski, C-573/17, EU:C:2019:530. 
siciones de una decisión marco, en este caso, las decisiones marco 2002/584 y $2008 / 909^{33}$.

La sentencia Poplawski comienza el razonamiento confirmando que el principio de primacía consagra la preeminencia del derecho de la Unión sobre el derecho de los Estados miembros e impone la obligación de garantizar la plena eficacia de las distintas normas de la Unión a todos los órganos e instituciones de los Estados miembros, sin que el derecho interno pueda afectar a la eficacia reconocida a esas distintas normas en el territorio de dichos Es$\operatorname{tados}^{34}$. Seguidamente el Tribunal vincula el principio de primacía con el de interpretación conforme y con el de responsabilidad de los Estados miembros por daños, concluyendo que "para garantizar la efectividad del conjunto de las disposiciones del derecho de la Unión, el principio de primacía obliga, en particular, a los órganos jurisdiccionales nacionales a interpretar, en la medida de lo posible, su Derecho interno de manera conforme con el derecho de la Unión y a reconocer a los particulares la posibilidad de obtener una reparación cuando sus derechos resulten lesionados por una violación del derecho de la Unión imputable a un Estado miembro». Esta vinculación tan estricta me parece discutible, ya que el principio de interpretación conforme y el de responsabilidad del Estado por daños a particulares causados por la violación de normas de la UE tienen sustantividad propia (López Escudero, 2019: 91-97).

Además, el Tribunal pone de manifiesto los efectos (de exclusión y de sustitución) del principio de primacía, indicando que «el juez nacional encargado de aplicar, en el ámbito de su competencia, las disposiciones del derecho de la Unión tendrá la obligación de garantizar la plena eficacia de tales disposiciones, dejando inaplicada si fuera necesario, y por su propia iniciativa, cualquier disposición contraria de la legislación nacional, aun posterior, sin que deba solicitar o esperar su previa eliminación por vía legislativa o mediante cualquier otro procedimiento constitucional $\aleph^{35}$.

33 Decisión Marco 2008/909/JAI del Consejo, de 27 de noviembre de 2008, relativa a la aplicación del principio de reconocimiento mutuo de sentencias en materia penal por las que se imponen penas u otras medidas privativas de libertad a efectos de su ejecución en la Unión Europea (DO 2008, L 327, p. 27), y Decisión Marco 2002/584/JAI del Consejo, de 13 de junio de 2002, relativa a la orden de detención europea y a los procedimientos de entrega entre Estados miembros (DO 2002, L 190, p. 1). Sentencia de 24 de junio de 2019, Poplawski, C-573/17, EU:C:2019:530, apdos. 53 y 54 .

35 Sentencia de 24 de junio de 2019, Poplawski, C-573/17, EU:C:2019:530, apdo. 58, que cita su jurisprudencia clásica plasmada recientemente en la Sentencia de 4 de diciembre de 2018, Minister for Justice and Equality y Commissioner of An Garda Síochána, C 378/17, EU:C:2018:979, apdo. 35. 
No obstante, el Tribunal afirma que los efectos de la primacía pueden verse condicionados por el efecto directo y que el principio de primacía no puede llevar a cuestionar la distinción esencial entre las disposiciones del derecho de la Unión que disponen de efecto directo y las que carecen de él, ni, por tanto, a establecer un régimen único de aplicación de todas las disposiciones del derecho de la Unión por los órganos jurisdiccionales nacionales. La primacía despliega sus efectos en caso de normas de la UE con efecto directo, pero el TJUE afirma que «no cabrá invocar, como tal, una disposición del derecho de la Unión carente de efecto directo en un litigio al que se aplique el derecho de la Unión, con el fin de excluir la aplicación de una disposición de derecho nacional que le sea contraria ${ }^{36}$. El Tribunal recuerda su jurisprudencia sobre la ausencia de primacía de las disposiciones de la CDFUE carentes de efecto directo $^{37}$ y sobre la inoperancia de la primacía el supuesto de aplicación de directivas en las relaciones horizontales, dada la ausencia de efecto directo horizontal de estas, para concluir que «un órgano jurisdiccional nacional no está obligado, sobre la base exclusivamente del derecho de la Unión, a abstenerse de aplicar una disposición de su derecho nacional contraria a una disposición del derecho de la Unión si esta última disposición carece de efecto directo» ${ }^{38}$.

Los efectos de la primacía son condicionados por el TJUE a la concurrencia del efecto directo de las disposiciones de la Unión en caso de conflicto con normas nacionales. Como en el asunto Poplawski se trataba de la primacía de las decisiones marco 2002/584 y 2008/909, que son normas que por prescripción del derecho originario carecen de efecto directo, el TJUE concluye que «un órgano jurisdiccional de un Estado miembro no está obligado, sobre la base exclusivamente del Derecho de la Unión, a excluir la aplicación de una disposición de su Derecho nacional contraria a esas Decisiones Marco» ${ }^{39}$, aunque posteriormente se extiende recordando al tribunal neerlandés remitente la obligación de interpretación conforme con estas decisiones marco de su derecho interno y dándoles indicaciones sobre la manera de llevarla a cabo.

36 Sentencia de 24 de junio de 2019, Poplawski, C-573/17, EU:C:2019:530, apdos. 6062.

37 El TJUE consideró que el juez nacional no está obligado, sobre la base exclusivamente del derecho de la Unión, a abstenerse de aplicar una disposición del derecho nacional incompatible con una disposición de la Carta de Derechos Fundamentales de la Unión Europea que, como su art. 27, carezca de efecto directo (Sentencia de 15 de enero de 2014, Association de médiation sociale, C 176/12, EU:C:2014:2, apdos. 46 a 48).

38 Sentencia de 24 de junio de 2019, Poplawski, C-573/17, EU:C:2019:530, apdos. 6468.

Ibid., apdo. 71 . 
La solución adoptada por la sentencia Poplawski conduce al debilitamiento de la primacía de las decisiones marco por el hecho de que se trata de normas del derecho de la UE carentes de efecto directo. El TJUE niega los efectos de exclusión y de sustitución de las decisiones marco respecto a las normas nacionales contrarias a sus disposiciones, de manera que los jueces nacionales deben seguir aplicando estas hasta que las autoridades de los Estados miembros procedan a su adecuación al contenido de las decisiones marco. Al igual que el abogado general Campos Sánchez-Bordona, considero que esta solución de la sentencia Poplawski choca con el principio de primacía del derecho de la UE, en cuya virtud la norma nacional contraria a una decisión marco no debería ser aplicada por un juez nacional ${ }^{40}$.

En mi opinión, la distinción entre el efecto de exclusión y el efecto de sustitución de la primacía de las decisiones marco habría permitido una solución más adecuada que la establecida por la sentencia Poplawski II. El efecto de exclusión de la primacía de las decisiones marco 2002/584 y 2008/909 habría supuesto para el juez nacional la obligación de inaplicar la norma neerlandesa contraria a estas normas de la UE. En este caso, se trataba fundamentalmente del art. 4, punto 6, de la Decisión Marco 2002/584, que establece un motivo de no ejecución facultativa de la ODE, con el fin de favorecer la reinserción social del condenado y de la norma neerlandesa que incorporaba incorrectamente esta facultad al derecho interno de los Países Bajos. En virtud del efecto de exclusión de la primacía de este art. 4, punto 6, de la Decisión Marco 2002/584, el juez nacional debería descartar la aplicación de las normas neerlandesas que lo incorporaban incorrectamente. El efecto de sustitución de la primacía de la disposición de Decisión Marco 2002/584 no operaría, porque se trata de una norma carente de efecto directo, pero el juez nacional aplicaría el derecho neerlandés que incorpora esta decisión marco excluyendo el motivo de no ejecución facultativa de la ODE destinado a favorecer la reinserción social del condenado, de manera que autorizaría la ejecución de la ODE ${ }^{41}$.

40 Conclusiones del abogado general Campos Sánchez-Bordona de 27 de noviembre de 2018, Poplawski, C-573/17, EU:C:2018:957, punto 105. Esta misma posición fue defendida por el abogado general Bot en sus conclusiones en el asunto Popławski I, C-579/15, EU:C:2017:116, puntos 76 a 91; y en el asunto Lada, C-390/16, EU:C:2018:65, puntos 106 a 118.

41 Según el abogado general Campos Sánchez-Bordona, «si el órgano jurisdiccional remitente se abstiene de aplicar el artículo 6, apartados 2, 3 y 5, de la OLW, implicará que, a falta en el derecho nacional de un motivo de no ejecución facultativa correspondiente al artículo 4, punto 6, de la Decisión Marco 2002/584, habrá de ejecutarse la ODE dictada el 7 de octubre de 2013 contra el Sr. Popławski por el Sąd Rejonowy w Poznaniu (Tribunal de Distrito de Poznan), mediante la que se solicita la ejecución 
Una adecuada distinción entre el efecto de exclusión y el efecto de sustitución de la primacía de las decisiones marco ${ }^{42}$ no habría llevado al TJUE en su sentencia Poplawski II a considerar que la falta de efecto directo de la decisión marco conlleva que el juez nacional no tiene la obligación de excluir la aplicación de las disposiciones de su derecho interno incompatibles con el derecho de la Unión. Esta jurisprudencia impide la aplicación uniforme y efectiva de una decisión marco. El sacrificio de la primacía ante la ausencia de efecto directo de una norma sin distinción entre el efecto de exclusión y el efecto de sustitución de la primacía no favorece, desde luego, la efectividad y la aplicación uniforme del derecho de la UE.

\section{LIMITACIÓN DE LA PRIMACÍA POR EL PRINCIPIO DE COSA JUZGADA}

Los efectos de la primacía no operan cuando chocan con el principio de cosa juzgada. Establecido para garantizar tanto la estabilidad del derecho y de las relaciones jurídicas como la buena administración de la justicia, el principio de cosa juzgada reviste una gran importancia tanto en el ordenamiento jurídico de la Unión como en los ordenamientos jurídicos nacionales y se traduce en la imposibilidad de impugnar las resoluciones judiciales que hayan adquirido firmeza tras haberse agotado las vías de recurso disponibles o tras expirar los plazos previstos para dichos recursos ${ }^{43}$.

La importancia de la cosa juzgada tiene su plasmación más relevante en su capacidad para impedir que el principio de primacía despliegue sus efectos en caso de conflicto entre normas de la UE y sentencia firme de un juez o tribunal nacional pronunciada en contravención de dichas normas. En este supuesto, el TJUE considera que el derecho de la Unión no obliga al juez nacional a descartar la aplicación de las normas procesales naciona-

de la pena dictada por ese órgano jurisdiccional. En la vista, quedó confirmado —en particular, por el Ministerio Fiscal — que la legislación neerlandesa cuenta, efectivamente, con un fundamento jurídico para llevar a cabo la entrega» (Conclusiones del abogado general Campos Sánchez-Bordona de 27 de noviembre de 2018, Poplawski, C-573/17, EU:C:2018:957, punto 119).

42 El abogado general Bot se refirió a la lógica de desvinculación entre el efecto «de sustitución» y "la invocabilidad de la exclusión» en sus conclusiones en el asunto Lada, C-390/16, EU:C:2018:65, punto 118. Sobre esta distinción en la doctrina, pueden verse Simon (2010) y Dougan (2007).

43 Sentencias de 10 de julio de 2014, Impresa Pizzarotti, C-213/13, EU:C:2014:2067, apdo. 58; de 6 de octubre de 2015, C-69/14, Târşia, EU:C:2015:662, apdo. 28, y de 29 de julio de 2019, Hochtief Solutions Magyarországi Fióktelepe, C 620/17, EU:C:2019:630, apdo. 54. 
les que confieren fuerza de cosa juzgada a una resolución judicial, aunque con ello fuera posible subsanar una situación nacional incompatible con él. No exige, pues, que para tener en cuenta la interpretación de una disposición pertinente del derecho UE, adoptada por el Tribunal de Justicia con posterioridad a la resolución de un órgano jurisdiccional con fuerza de cosa juzgada, este deba reconsiderar sistemáticamente dicha resolución ${ }^{44}$. En definitiva, el efecto de suspensión de la aplicación de la norma nacional contraria, que conlleva la primacía, no alcanza a tumbar una sentencia firme de un juez nacional dictada en aplicación de una norma interna contraria al derecho de la UE.

Ahora bien, cuando las normas procesales nacionales contemplen la posibilidad de que el tribunal nacional reconsidere una resolución con fuerza de cosa juzgada con objeto de restablecer la conformidad de la situación derivada de dicha resolución con el derecho nacional, esta misma vía debe ser utilizada por el juez nacional para dar operatividad al principio de primacía y restablecer la conformidad de la relación jurídica con el derecho de la Unión. La consecución de la efectividad del derecho de la Unión debe ponerse en práctica de acuerdo con los principios de equivalencia y de efectividad ${ }^{45}$. Aquí se trata de que opere la primacía del derecho de la UE en contra del principio de cosa juzgada, cuando el juez nacional tenga una vía procesal en su derecho interno que permita levantar el efecto de cosa juzgada por violación del derecho de la Unión.

No obstante, el TJUE ha impuesto ${ }^{46}$ al juez nacional, de forma excepcional, la aplicación de la primacía en contra del principio de cosa juzgada en algunos casos. En especial, destaca la jurisprudencia Lucchini, según la cual no es oponible la cosa juzgada del derecho nacional a la primacía del derecho de la UE cuando aquella supone un obstáculo para la recuperación de una ayuda de Estado concedida en infracción del derecho de la Unión y cuya incompa-

44 Sentencias de 10 de julio de 2014, Impresa Pizzarotti, C-213/13, EU:C:2014:2067, apdos. 59 y 60; de 6 de octubre de 2015, Târşia, C-69/14, EU:C:2015:662, apdos. 29 y 38, y de 24 de octubre de 2018, XC y otros (C-234/17, EU:C:2018:853), apdos. 53 y 54 . Véase el interesante comentario sobre esta última sentencia de Turmo (2019).

45 Sentencias de 29 de julio de 2019, Hochtief Solutions Magyarországi Fióktelepe, C-620/17, EU:C:2019:630, apdo. 60, y de 11 de septiembre de 2019, Calin, C-676/17, EU:C:2019:170, apdo. 29.

El TJUE también ha impuesto la obligación a los órganos administrativos nacionales, si se dan ciertas condiciones, de revisar las resoluciones administrativas firmes para tomar en consideración una interpretación efectuada posteriormente por el Tribunal de Justicia (Sentencia de 13 de enero de 2004, Kühne \& Heitz, C-453/00, EU:C:2004:17, apdo. 28)S. 
tibilidad con el mercado común había sido declarada por una decisión firme de la Comisión ${ }^{47}$. Como la resolución judicial nacional se adoptó en violación del reparto de competencias entre los Estados miembros y la UE en materia de ayudas de Estado, era manifiestamente ilegal y, por lo tanto, nunca pudo adquirir fuerza de cosa juzgada ${ }^{48}$.

\section{SUSPENSIÓN TEMPORAL DE LA PRIMACÍA}

En varias sentencias recientes relativas en la mayoría de los casos a la protección del medio ambiente y, en especial, a la obligación de realizar evaluaciones de impacto ambiental de proyectos, planes y programas, el TJUE ha flexibilizado la aplicación del principio de primacía, permitiendo a los jueces nacionales suspender temporalmente la ejecución del mandato de inaplicación de la norma nacional contraria al derecho UE.

El primer caso en que el TJUE aceptó esta posibilidad fue el asunto Winner Wetten, relativo a una normativa alemana sobre el monopolio de apuestas deportivas. El juez alemán remitente deseaba saber si el efecto de exclusión de la normativa nacional declarada contraria a los art. 43 y $49 \mathrm{CE}$, que se deriva del principio de primacía, podía suspenderse durante el tiempo necesario para adecuar dicha normativa a las mencionadas disposiciones del tratado, con objeto de proteger el orden social y a los ciudadanos contra los riesgos ligados a los juegos de azar ${ }^{49}$. Por analogía con su jurisprudencia sobre el mantenimiento de los efectos de un acto de la Unión anulado o declarado inválido, con objeto de impedir la existencia de un vacío jurídico hasta que un nuevo acto sustituya al anulado, por consideraciones imperiosas de seguridad jurídica, el TJUE admitió, con carácter excepcional, la posibilidad de suspender provisionalmente el efecto de exclusión que ejerce una norma de la Unión directamente aplicable sobre el derecho nacional contrario a ella, pero bajo su control, en caso de concurrencia de consideraciones imperiosas de seguridad jurídica, que en el caso de autos no se daban respecto a la normativa alemana ${ }^{50}$.

47 Sentencia de 18 de julio de 2007, Lucchini (C-119/05, EU:C:2007:434), apdo. 63. Véase el comentario de Martín Rodríguez (2007)

48 Sentencias de 3 de septiembre de 2009, Fallimento Olimpiclub (C-2/08, EU:C:2009: 506), apdo. 25, y de 10 de julio de 2014, Impresa Pizzarotti (C-213/13, EU:C:2014: 2067), apdo. 61.

49 Sentencia de 8 de septiembre de 2010, Winner Wetten, C-409/06, EU:C:2010:503, apdo. 63.

50 Ibid., apdos. 66 y 67. 
Esta jurisprudencia ha sido confirmada y desarrollada con varias sentencias en materia de medio ambiente. La sentencia Association France Nature Environnement ${ }^{51}$ afirmó que el Tribunal de Justicia puede, con carácter excepcional y en atención a consideraciones imperiosas de seguridad jurídica, suspender provisionalmente el efecto de exclusión que ejerce una norma de la Unión sobre el derecho nacional contrario a ella. Esta posibilidad se la reserva en exclusiva el TJUE, porque si los órganos jurisdiccionales nacionales estuvieran facultados para otorgar primacía a las normas nacionales contrarias al derecho de la Unión, aunque fuera provisionalmente, se menoscabaría la aplicación uniforme de este último ordenamiento.

Además de ser una prerrogativa exclusiva suya, el TJUE indica que habilitará a los jueces nacionales de manera excepcional a suspender temporalmente la aplicación del principio de primacía y a mantener los efectos de la norma nacional contraria a la norma de la UE en función de las circunstancias del caso, siendo imprescindible la concurrencia de una exigencia imperiosa de interés general capaz de justificar dicha suspensión y con el respecto de condiciones estrictas. En las sentencias Inter-Environnement Wallonie y Terre wallonne y Association France Nature Environnement, la suspensión temporal de la primacía de las normas de la Directiva 2001/42 fue aceptada por el TJUE para proteger el medio ambiente, pero con la imposición de condiciones estrictas para seguir aplicando provisionalmente la norma nacional contraria al derecho de la UE ${ }^{52}$.

Teniendo en cuenta dicha jurisprudencia, en el reciente asunto sobre la prolongación de la actividad de los reactores nucleares belgas de Doel 1 y Doel 2 diez años más, sin haberse realizado previamente un estudio de impacto ambiental ni un procedimiento que permita la participación del público, el Tribunal de Justicia consideró que estaba justificado excepcionalmente mantener los efectos de las medidas belgas por consideraciones imperiosas ligadas a la seguridad de suministro de electricidad en Bélgica. El TJUE permite al juez belga mantener de forma temporal los efectos de medidas nacionales que se habían adoptado incumpliendo las obligaciones impuestas por las directivas EIA y hábitats solamente si, en la hipótesis de una anulación o una suspensión de los efectos de esas medidas, existiera una amenaza real y grave de corte del suministro eléctrico del Estado miembro afectado a la que no se pudiera hacer

51 Sentencia de 28 de julio de 2016, Association France Nature Environnement, C-379/15, EU:C:2016:603, apdo. 33. Véase el comentario de Sowery (2017).

52 Sentencias de 28 de febrero de 2012 Inter-Environnement Wallonie y Terre wallonne, C-41/11, EU:C:2012:103), y de 28 de julio de 2016, Association France Nature Environnement, C-379/15, EU:C:2016:603, apdo. 43. 
frente por otros medios y mediante otras alternativas, en particular en el marco del mercado interior ${ }^{53}$.

Esta suspensión temporal de la aplicación del principio de primacía y de su principal efecto, que es la inaplicación de la norma nacional contraria, me parece razonable, porque obedece a consideraciones de seguridad jurídica orientadas a evitar vacíos normativos que menoscaben la protección de intereses sociales importantes, como la protección del medio ambiente o la garantía del suministro de electricidad en un Estado miembro.

\section{LOS LÍMITES EXTERNOS A LA PRIMACÍA DEL DERECHO DE LA UNIÓN EUROPEA Y SU RELACIÓN CON LAS CONSTITUCIONES NACIONALES}

El Tribunal de Justicia ha afirmado la primacía del derecho de la Unión sobre las normas nacionales de manera incondicional y absoluta, ya que se aplica a todos los distintos tipos de normas existentes en el derecho de la UE y opera sobre todas las normas de los derechos internos de los Estados miembros, incluidas las de rango constitucional, y tanto si son anteriores como posteriores a la norma de la UE de contenido contrario. Por ello, en virtud del principio de primacía, no puede admitirse que normas de derecho nacional, aunque sean de rango constitucional, menoscaben la unidad y la eficacia del derecho de la Unión ${ }^{54}$. Según el TJUE, la primacía opera, también, sobre las

53 Sentencia de 29 de julio de 2019, Inter-Environnement Wallonie y Bond Beter Leefmilieu Vlaanderen C-411/17, EU:C:2019:622, apdos. 179-181.

54 Sentencias de 17 de diciembre de 1970, Internationale Handelsgesellschaft, 11/70, EU:C:1970:114, apdo. 3; de 13 de diciembre de 1979, Hauer, 44/79, EU:C:1979:290, apdo. 14, y de 15 de enero de 2013, Križan y otros, C416/10, EU:C:2013:8, apdo. 70. Es jurisprudencia asentada que «en virtud del principio de primacía del Derecho de la Unión, que es una característica esencial del ordenamiento jurídico de la Unión [v. el dictamen 1/91 (Acuerdo EEE-I), de 14 de diciembre de 1991, EU:C:1991:490, apartado 21, y el dictamen 1/09 (Acuerdo sobre la creación de un sistema unificado de resolución de litigios sobre patentes), de 8 de marzo de 2011, EU:C:2011:123, apartado 65], la invocación por un Estado miembro de las disposiciones del derecho nacional, aun si son de rango constitucional, no puede afectar a la eficacia del Derecho de la Unión en el territorio de ese Estado» (Sentencia de 8 de septiembre de 2010, Winner Wetten, C409/06, EU:C:2010:503, apdo. 61). Esta jurisprudencia ha sido recientemente reiterada por la Sentencia de 4 de diciembre de 2018, Minister for Justice and Equality y Commissioner of An Garda Síochána, C-378/17, EU:C:2018:979, apdo. 49. 
normas internas de rango constitucional. Así, la sentencia Krei $\bar{P}^{5}$ consideró incompatible con la Directiva 76/207/CEE ${ }^{56}$ una medida nacional, como era el caso del art. 12 de la Ley Fundamental alemana, que reservaba exclusivamente a los hombres el servicio en las fuerzas armadas.

$\mathrm{El}$ art. 53 de la Carta de Derechos Fundamentales confirma que, cuando un acto del derecho de la Unión requiere medidas nacionales para su ejecución, las autoridades y tribunales nacionales siguen estando facultados para aplicar estándares nacionales de protección de los derechos fundamentales, pero ello es así «siempre que esa aplicación no afecte al nivel de protección previsto por la Carta, según su interpretación por el Tribunal de Justicia, ni a la primacía, la unidad y la efectividad del derecho de la Unión ${ }^{57}$.

Esta primacía incondicional y absoluta del derecho de la UE resulta difícilmente asimilable desde la perspectiva de ordenamientos internos articulados sobre la base de una jerarquía normativa en la que la Constitución ocupa el lugar supremo. El eventual conflicto entre Constitución y derecho de la UE, ambos con vocación de supremacía, reviste especial gravedad en los Estados miembros que disponen de un tribunal constitucional, cuya función esencial es garantizar la supremacía de la Constitución. Ello explica que los tribunales constitucionales de Alemania e Italia, aun aceptando las consecuencias del efecto directo y de la primacía del derecho de la UE, se hayan reservado la posibilidad de ejercer un control de constitucionalidad en casos hipotéticos extremos de contradicción de las normas de la Unión con los principios constitucionales básicos, en especial con los derechos fundamentales constitucionalmente protegidos. A ellos se han unido en fechas recientes los tribunales de otros Estados miembros, a medida que las normas de la UE inciden cada vez con mayor intensidad en materias vinculadas con el núcleo duro de la soberanía nacional, como el derecho penal y las normas procesales penales ${ }^{58}$.

55 Sentencia de 11 de enero de 2000, Kreil, C-295/98, EU:C:2000:2.

56 Directiva 76/207/CEE del Consejo, de 9 de febrero de 1976, relativa a la aplicación del principio de igualdad de trato entre hombres y mujeres en lo que se refiere al acceso al empleo, a la formación y a la promoción profesionales, y a las condiciones de trabajo (DO L 39, p. 40).

57 Sentencia de 26 de febrero de 2013, Melloni, C-399/11, EU:C:2013:107, apdo. 60.

58 El Tribunal Constitucional checo, en la sentencia de 31 de enero de 2012, relativa a las "pensiones eslovacas", declaró ultra vires la Sentencia de 22 de junio de 2011, Landtovà, C399/09, EU:C:2011:415 (Czech Constitutional Court, n. Pl. ÚS 5/12, Slovak Pensions XVII). El Tribunal Constitucional Federal alemán, tanto en su sentencia de 15 de diciembre de 2015, que tenía por objeto la ejecución de una orden europea de detención en el marco de una sentencia de condena pronunciada in absentia (BVerfG, 2 BvR 2735/14), como en su sentencia de 26 de junio de 2016 
El Tribunal Constitucional español no ha sido ajeno a estas reticencias y mostró inicialmente una actitud renuente hacia el derecho de la UE, considerando que la aplicación del principio de primacía era competencia de los tribunales españoles de la jurisdicción ordinaria. Esta actitud varió con la Declaración 1/2004 en la que acepta con claridad la primacía de las normas de la Unión, aunque haciendo un razonamiento teórico en el que salva la supremacía de la Constitución española ${ }^{59}$. En efecto, afirmó nuestro Tribunal Constitucional que

(BVerfG, 2 BvR 2728/13), que cierra la «saga Gauweiler», no aplicó los contralímites pero los invocó, exhortando al Tribunal de Justicia a respetar los principios que constituyen el núcleo duro de la identidad constitucional nacional. El Tribunal Constitucional húngaro, en su sentencia de 16 de diciembre de 2016, relativa a la obligación de respetar las cuotas para el reparto equitativo de los solicitantes de asilo entre los Estados miembros, hizo referencia explícita a la trilogía SolangeMaastricht-Lisboa [Decision 22/2016 (XII.5), AB on the Interpretation of Article E) (2) of the Fundamental Law (Const. Ct. Hung.)], dejando claro que la tutela de la identidad constitucional no puede ser puesta en discusión por las exigencias de la integración europea y afirmando la propia competencia para examinar si el ejercicio conjunto con otros Estados miembros a través de las instituciones de la UE de las competencias transferidas ex art. E) (2) de la Ley Fundamental de Hungría, que contiene la cláusula de apertura de este país a la UE, viola o no la dignidad humana, otros derechos fundamentales, la soberanía de Hungría o su identidad constitucional. El Tribunal Supremo danés, en su sentencia de 6 de diciembre de 2016, rechazó aplicar la Sentencia de 19 de abril de 2016, Dansk Industri (C-441/14, EU:C:2016:278), considerando que violaba el reparto de competencias fijado en la ley danesa de adhesión a la UE [UfR 2017.824H (case no 15/2014, DI, acting on behalf of Ajos A/S v Estate of A)].

59 Declaración del Tribunal Constitucional español 1/2004, de 13 de diciembre, BOE n. ${ }^{\circ}$, de 4 de enero de 2005, pp. 5-21. Su FJ 4 afirma que "primacía y supremacía son categorías que se desenvuelven en órdenes diferenciados. Aquélla, en el de la aplicación de normas válidas; ésta, en el de los procedimientos de normación. La supremacía se sustenta en el carácter jerárquico superior de una norma y, por ello, es fuente de validez de las que le están infraordenadas, con la consecuencia, pues, de la invalidez de éstas si contravienen lo dispuesto imperativamente en aquélla. La primacía, en cambio, no se sustenta necesariamente en la jerarquía, sino en la distinción entre ámbitos de aplicación de diferentes normas, en principio válidas, de las cuales, sin embargo, una o unas de ellas tienen capacidad de desplazar a otras en virtud de su aplicación preferente o prevalente debida a diferentes razones. Toda supremacía implica, en principio, primacía (de ahí su utilización en ocasiones equivalente, así en nuestra Declaración 1/1992, FJ 1), salvo que la misma norma suprema haya previsto, en algún ámbito, su propio desplazamiento o inaplicación». 
la supremacía de la Constitución es, pues, compatible con regímenes de aplicación que otorguen preferencia aplicativa a normas de otro ordenamiento diferente del nacional siempre que la propia Constitución lo haya así dispuesto, que es lo que ocurre exactamente con la previsión contenida en su artículo 93, mediante el cual es posible la cesión de competencias derivadas de la Constitución a favor de una institución internacional así habilitada constitucionalmente para la disposición normativa de materias hasta entonces reservadas a los poderes internos constituidos y para su aplicación a éstos. En suma, la Constitución ha aceptado, ella misma, en virtud de su artículo 93, la primacía del Derecho de la Unión en el ámbito que a ese Derecho le es propio [...], y así han sido las cosas entre nosotros desde la incorporación de España a las Comunidades Europeas en 1986. Entonces se integró en el ordenamiento español un sistema normativo autónomo, dotado de un régimen de aplicabilidad específico, basado en el principio de prevalencia de sus disposiciones propias frente a cualesquiera del orden interno con las que pudieran entrar en contradicción.

El TC español ha utilizado la vía del art. 24.2 de la Constitución española, que protege el derecho a la tutela judicial efectiva, para intervenir en la aplicación del principio de primacía por los jueces españoles y en el uso por parte de estos del mecanismo prejudicial ${ }^{60}$.

60 La STCE 37/2019, de 26 de marzo (BOE núm. 99, de 25 de abril de 2019), FJ 4, sistematiza la jurisprudencia del TC de la manera siguiente:

«a) Resulta contrario al derecho a un proceso con todas las garantías (art. 24.2 CE), dejar de aplicar una norma interna (tenga esta rango de ley o no) sin plantear cuestión prejudicial ante el Tribunal de Justicia de la Unión Europea, cuando exista una "duda objetiva, clara y terminante" sobre esa supuesta contradicción [SSTC 58/2004, FFJJ 9 a 14; 232/2015, FJ 5 a)]. Tal duda objetiva puede derivar:

- (i) del hecho de existir un criterio generalizado de los tribunales españoles acerca de la compatibilidad entre ambas normas, que el órgano judicial no desvirtúa mediante una motivación específica en la resolución impugnada en amparo;

- (ii) porque pese a haberse dictado una o más resoluciones por el Tribunal de Justicia de la Unión Europea referentes a dicha norma nacional, ninguna se ha pronunciado directamente sobre las cuestiones que ahora se suscitan;

- (iii) o bien por la conjunción de ambas circunstancias (STC 58/2004, FFJJ 13$14)$;

b) Resulta igualmente contrario al derecho a un proceso con todas las garantías (art. 24.2 CE), por alteración del sistema de fuentes: inaplicar una norma interna sin plantear cuestión prejudicial ante el Tribunal de Justicia de la Unión Europea cuando se fundamente dicha decisión en la doctrina del "acto aclarado", en los casos en que tal doctrina no puede ser invocada; es decir, cuando no sea posible afirmar que "la cuestión planteada es materialmente idéntica a una que ya fue ob- 
La aceptación de la primacía por el Tribunal Constitucional español se vio corroborada por la interposición por parte de este de una cuestión prejudicial al Tribunal de Justicia en el asunto Melloni, a raíz de la cual el Tribunal Constitucional tuvo que cambiar su jurisprudencia sobre el art. 24, apdo. 2, de la Constitución y las extradiciones en casos de condenas en rebeldía en su Sentencia 26/2014, de 13 de febrero ${ }^{61}$. Ello supone la aceptación de la primacía, aunque las reticencias del Tribunal Constitucional se perciben en su razonamiento, porque incluyó un FJ segundo en el que mencionaba la posibilidad de invocar contralímites a la primacía del derecho de la UE para preservar la «soberanía del Estado, de nuestras estructuras constitucionales básicas y del sistema de valores y principios fundamentales consagrados en nuestra Constitución, en el que los derechos fundamentales adquieren sustantividad propia», y porque el Tribunal Constitucional resolvió el caso modificando su interpretación del art. 24, apdo. 2, de la Constitución y no aplicando directamente la sentencia del TJUE.

Estas reticencias a la aceptación de la primacía absoluta e incondicional de cualquier norma de la UE sobre todo tipo de normas internas, incluidas las constitucionales, generan lo que llamamos límites externos al principio de

jeto anteriormente de una decisión con carácter prejudicial en un asunto análogo" (STJUE de 6 de octubre de 1982, asunto 283/81, Cilfit, apartado 13) como, por ejemplo, se examinó en la ya citada STC 194/2006;

c) En sentido contrario a lo anterior, "dejar de plantear la cuestión prejudicial y aplicar una ley nacional supuestamente contraria al Derecho de la Unión no vulnera el derecho a la tutela judicial efectiva si esa decisión es fruto de una exégesis racional de la legalidad ordinaria, pues solo estos parámetros tan elevados forman parte de los derechos consagrados en el art. 24 CE" [STC 232/2015, FJ 5 b), con cita de las anteriores SSTC 27/2013, de 11 de febrero, FJ 7; 212/2014, de 18 de diciembre, FJ 3, y 99/2015, de 25 de mayo, FJ 3];

d) Asimismo, cumpliéndose con los requisitos de la doctrina del "acto aclarado", también hemos dicho que "corresponde a este Tribunal velar por el respeto del principio de primacía del Derecho de la Unión cuando exista una interpretación auténtica efectuada por el propio Tribunal de Justicia de la Unión Europea. En estos casos, el desconocimiento y preterición de esa norma de Derecho de la Unión, tal y como ha sido interpretada por el Tribunal de Justicia, puede suponer una 'selección irrazonable y arbitraria de una norma aplicable al proceso', lo cual puede dar lugar a una vulneración del derecho a la tutela judicial efectiva” [STC 232/2015, FJ 5 c), con cita de las anterior STC 145/2012, de 2 de julio, FFJJ 5 y 6; en igual sentido, SSTC 148/2016, de 19 de septiembre, FJ 5 b); 162/2016, de 3 de octubre, FJ 2, y 75/2017, de 19 de junio, FJ 2]». 
primacía. La calificación de «externos» se debe, como resulta evidente, a que provienen de órganos jurisdiccionales nacionales, en particular de los tribunales constitucionales o supremos.

El análisis de la aceptación de la primacía en los derechos internos y los límites externos que las jurisdicciones constitucionales han ido sugiriendo ha generado un largo debate doctrinal que no es posible abordar en este editorial $^{62}$.

Me voy a concentrar en el estudio del reciente desarrollo jurisprudencial establecido por el TJUE en relación con la aplicación de los efectos del principio de primacía por los jueces nacionales en los casos en que la inaplicación por el juez nacional de la norma interna contraria al derecho de la UE provoca la violación de un derecho fundamental protegido por la constitución nacional. En este supuesto, el TJUE, flexibilizando su jurisprudencia clásica, ha aceptado un límite externo a la operatividad de la primacía cuando la inaplicación de la norma nacional contraria al derecho de la UE provoca la violación de un derecho fundamental.

Esta limitación al principio de primacía, conectada con los límites internos y en especial con el relativo al respecto de la cosa juzgada, ha sido reconocida por el TJUE en la histórica sentencia M.A.S. y M.B., en la que se inspiran las posteriores sentencias Kolev y Dzivev ${ }^{63}$.

El conflicto radical entre derecho de la UE y derecho constitucional nacional es un conflicto insuperable desde el punto de vista lógico en el estadio actual del proceso de integración. Sin embargo, dicho conflicto es difícil que se produjera, según la doctrina (Rodríguez Iglesias y López Escudero, 2010: 720), por las dos razones siguientes: por una parte, todos los Estados miembros disponen de un fundamento constitucional explícito o implícito para ser miembros de la UE, que debe ser suficiente para admitir que las normas dictadas por la UE en ejercicio de las competencias que esta ha asumido prevalezcan en caso de conflicto incluso sobre las disposiciones de la propia constitución de carácter no fundamental; por otra parte, la hipótesis de un conflicto radical entre el derecho de la UE y los principios fundamentales del derecho constitucional nacional es difícilmente imaginable en la realidad, ya que, por la vía de los principios generales del derecho comunes a los sistemas jurídicos de los Estados miembros, el derecho de la Unión integra los fun-

62 Véase, por todos, el trabajo de Rodríguez Iglesias y Valle Gálvez (1997).

63 Sentencias de 5 de diciembre de 2017, M.A.S. y M. B., C42/17, EU:C:2017:936; 5 de junio de 2018, Kolev y otros, C-612/15, EU:C:2018:39217, y de enero de 2019, Dzivev y otros, C-310/16, EU:C:2019:30. 
damentos esenciales de los sistemas constitucionales nacionales, que, como Estados democráticos de derecho, comparten valores comunes ${ }^{64}$.

No obstante, estos dos factores no han conseguido evitar un conflicto directo entre el derecho UE y el derecho constitucional italiano en el reciente asunto M.A.S. y M.B. ${ }^{65}$. Dicha controversia se ha producido como consecuencia de la sentencia Taricco ${ }^{66}$, en la que el Tribunal de Justicia consideró que las disposiciones del Código Penal italiano sobre la interrupción de la prescripción en el marco de un procedimiento penal relativo a fraudes graves en materia de IVA, que ampliaban el plazo de prescripción en tan solo una cuarta parte de su duración inicial, podían ser contrarias a las obligaciones impuestas a los Estados miembros por el art. 325 TFUE, apdos. 1 y 2, para proteger los intereses financieros de la UE. Dicha infracción se producía porque estas normas italianas sobre la prescripción impedían, en el marco de un procedimiento relativo a infracciones graves en materia de IVA, la aplicación de sanciones efectivas y disuasorias para luchar contra los fraudes que afecten a los intereses financieros de la Unión.

En esta tesitura, la aplicación de la primacía del art. 325 TFUE, apdos. 1 y 2, debía permitir al juez nacional garantizar la plena eficacia del derecho de la Unión, dejando si es preciso sin aplicación las referidas disposiciones nacionales limitativas de la prescripción, sin solicitar o esperar su previa derogación por el legislador o mediante cualquier otro procedimiento constitucional ${ }^{67}$. En este caso, se trataba de que operase el efecto de exclusión de la primacía, ya que no había armonización normativa por parte de la UE que permitiera aplicar el efecto de sustitución de la primacía, al no existir normas de la Unión sobre la prescripción de los delitos por fraudes al IVA ${ }^{68}$.

64 El art. 4 TUE, apdo. 2, introducido por el Tratado de Lisboa, ha venido a dar seguridad a los Estados miembros respecto a las posibles intromisiones de la UE en ámbitos centrales de su soberanía, ya que afirma que «la Unión respetará la igualdad de los Estados miembros ante los Tratados, así como su identidad nacional, inherente a las estructuras fundamentales políticas y constitucionales de éstos, también en lo referente a la autonomía local y regional». Sentencia de 5 de diciembre de 2017, M.A.S. y M. B., C-42/17, EU:C:2017:936. Entre los numerosos comentarios a esta sentencia, me limito a mencionar los de Amalfitano (2018); Dubout (2018); Faggiani (2018), y Rauchegger (2018).

66 Sentencia de 8 de septiembre de 2015, Taricco y otros, C-105/14, EU:C:2015:555.

67 Ibid., apdos. 49 y 51.

68 Con posterioridad se ha llevado a cabo en esta materia una armonización parcial mediante la adopción de la Directiva (UE) 2017/1371, del Parlamento Europeo y del Consejo, de 5 de julio de 2017, sobre la lucha contra el fraude que afecta a los intereses financieros de la Unión a través del Derecho penal (DO 2017, L 198, p. 29). 
Ante la posibilidad de que la inaplicación de la norma interna italiana sobre la limitación de la prescripción provocara la inculpación de infractores en violación del principio de legalidad penal del art. 25 de la Constitución italiana, el TJUE añadió simplemente que «si el órgano jurisdiccional nacional decide dejar sin aplicación las disposiciones nacionales controvertidas, habrá de velar igualmente por que se respeten los derechos fundamentales de las personas afectadas. En efecto, estas últimas podrían verse imponer sanciones que, con toda probabilidad, habrían evitado si se hubieran aplicado las disposiciones de Derecho nacional» ${ }^{69}$.

Posiblemente, el tenor del auto de planteamiento de la cuestión prejudicial, que no hacía hincapié en la repercusión sobre el ordenamiento constitucional italiano de la inaplicación de la norma sobre la prescripción y que no insistía en el carácter material de la prescripción en su derecho interno, provocó una sentencia de la gran sala del TJUE cuyas consecuencias no se sopesaron adecuadamente. Al art. 325 TFUE se le confería un efecto directo in malam partem para los acusados de fraudes al IVA y en favor del Estado en una relación jurídica vertical, ya que la inaplicación de la norma italiana sobre prescripción provocaba el mantenimiento de su inculpación y la no extinción de la acusación penal contra ellos ${ }^{70}$.

El Tribunal Constitucional italiano consideró que la inaplicación de las disposiciones del Código Penal limitativas de la prescripción tendría como consecuencia que se les aplicaran a los imputados sanciones más graves que las vigentes en el momento de la comisión del presunto delito, chocando ello con el principio de legalidad penal amparado por el art. 25 de la Constitución italiana ${ }^{71}$. Para no recurrir a su doctrina de los contralímites, el Tribunal Constitucional italiano preguntó por vía prejudicial al TJUE cómo aplicar la jurisprudencia Taricco $I$.

69 Sentencia de 8 de septiembre de 2015, Taricco y otros, C-105/14, EU:C:2015:555, apdos. 49 y 51.

70 Me remito al interesante análisis de Perlo (2017).

71 Este principio de legalidad penal se extiende a las normas de prescripción previstas en el ordenamiento jurídico italiano, cuyo carácter material implica que esas reglas sean razonablemente previsibles para los justiciables en el momento de la comisión de las infracciones que se les imputan sin que puedan ser modificadas in peius con carácter retroactivo $\mathrm{y}$, por otra parte, conlleva la exigencia de que toda normativa nacional relativa al régimen de imputación debe estar fundamentada en una base legal suficientemente precisa para poder delimitar y orientar la apreciación del juez nacional. 
Las conclusiones del abogado general Bot en el caso M.A.S. y M.B. ${ }^{72}$ invitaban al TJUE a no modificar la doctrina Taricco y no dejaban prever un cambio jurisprudencial. Bot consideraba que la Corte constituzionale italiana no habría tenido que invocar los contralímites, puesto que la aplicación de un plazo de prescripción más largo, derivado de la obligación establecida en la sentencia Taricco del TJUE, no violaría la identidad constitucional nacional (art. 4.2 TUE) $)^{73}$.

El TJUE va a seguir en su sentencia M.A.S. y M.B. un enfoque opuesto al sugerido por su abogado general. La posibilidad de «revisar» la solución Taricco se abre al señalar «corresponde al Tribunal de Justicia precisar, habida cuenta de las interrogantes que ha planteado el tribunal remitente respecto a este principio [de legalidad penal] y que no habían sido puestas en su conocimiento en el asunto que dio lugar a la sentencia Taricco, la interpretación llevada a cabo por dicha sentencia del artículo 325 TFUE, apartados 1 y $2 »^{74}$. No obstante, el TJUE mantuvo en su sentencia M.A.S. $y$ M.B. su jurisprudencia Taricco, reafirmando que «corresponde por tanto a los órganos jurisdiccionales nacionales competentes dar plenos efectos a las obligaciones que resultan del artículo 325 TFUE, apartados 1 y 2, y dejar sin aplicación disposiciones internas, en particular en el ámbito de la prescripción, que, en el marco de un procedimiento relativo a infracciones graves en materia de IVA, impiden la aplicación de sanciones efectivas y disuasorias para luchar contra los fraudes que afecten a los intereses financieros de la Unión» ${ }^{75}$.

Además, el TJUE vuelve a reiterar que la primacía del derecho de la UE obliga también al legislador nacional a establecer reglas de prescripción que permitan cumplir con las obligaciones que resultan del art. 325 TFUE, para garantizar que el régimen nacional de prescripción en materia penal no conduzca a la impunidad de un número considerable de casos de fraude grave en materia de IVA o no sea, para las personas acusadas, más severo en casos de

72 Conclusiones del abogado general Bot de 18 de julio de 2017, M.A.S. y M.B., C-42/17, EU:C:2017:564.

73 Ibid., puntos 169-187, en los que se ocupa expresamente de la cuestión relativa al respeto de la identidad constitucional de la República Italiana. Al respecto, véase Bin (2017).

74 Sentencia de 5 de diciembre de 2017, M.A.S. y M. B., C-42/17, EU:C:2017:936, apdo. 28.

75 Sentencias de 8 de septiembre de 2015, Taricco y otros, C-105/14, EU:C:2015:555, apdos. 49 y 58, y de 5 de diciembre de 2017, M.A.S. y M. B., C42/17, EU:C:2017:936, apdo. 39. 
fraudes que afecten a los intereses financieros del Estado miembro de que se trate que en los que afecten a los intereses financieros de la Unión ${ }^{76}$.

Hasta aquí nada nuevo en el razonamiento del TJUE, pero su argumentación (por cierto, no demasiado clara) cambia a partir del apdo. 46 de la sentencia M.A.S. y M.B., que retoma el apdo. 43 de su sentencia Taricco, en el que decía que los órganos jurisdiccionales nacionales competentes, cuando, en el curso de procedimientos abiertos, decidan dejar sin aplicación las disposiciones del Código Penal controvertidas, habrán de velar por que se respeten los derechos fundamentales de las personas acusadas de haber cometido una infracción penal. Seguidamente recuerda su jurisprudencia Melloni y Akerberg Fransson, según la cual las autoridades y tribunales nacionales están facultados para aplicar estándares nacionales de protección de los derechos fundamentales, siempre que esa aplicación no afecte al nivel de protección previsto por la Carta, según su interpretación por el Tribunal de Justicia, ni a la primacía, la unidad y la efectividad del derecho de la Unión ${ }^{77}$.

A continuación, se hace eco del impacto negativo sobre el principio de legalidad de los delitos y las penas que la inaplicación por los jueces italianos de las normas de prescripción en los términos de la sentencia Taricco, según las indicaciones del Tribunal Constitucional italiano en su auto de remisión de la cuestión prejudicial. Seguidamente, el TJUE pone de manifiesto que, tanto en el ordenamiento jurídico de la Unión (art. 49 CDFUE) como en los ordenamientos jurídicos nacionales, el principio de legalidad de los delitos y las penas conlleva exigencias relativas a la previsibilidad, la precisión y la irretroactividad de la ley penal aplicable, que, en el caso del ordenamiento jurídico italiano, también rigen para el régimen de prescripción relativo a las infracciones penales en materia del IVA ${ }^{78}$.

76 Sentencia de 5 de diciembre de 2017, M.A.S. y M. B., C-42/17, EU:C:2017:936, apdo. 41. El Tribunal ha reafirmado después que corresponde al legislador nacional modificar su normativa y garantizar que la regulación procesal de la acción penal incoada por infracciones que afecten a los intereses financieros de la Unión no esté configurada de modo que presente, por razones inherentes a dicho régimen, un riesgo sistémico de impunidad de los hechos constitutivos de tales infracciones, así como garantizar la protección de los derechos fundamentales de las personas acusadas (sentencias de 5 de junio de 2018, Kolev y otros, C-612/15, EU:C:2018:392, apdo. 65, y de17 de enero de 2019, Dzivev y otros, C-310/16, EU:C:2019:30, apdo. 31).

77 Sentencia de 26 de febrero de 2013, Åkerberg Fransson, C 617/10, EU:C:2013:105, apdo. 29.

78 Sentencia de 5 de diciembre de 2017, M.A.S. y M. B., C 42/17, EU:C:2017:936, apdos. 51-58. 
Finalmente, el TJUE en su sentencia M.A.S. y M.B. pasa la solución Taricco por el filtro del principio de legalidad y señala que corresponde al juez nacional verificar si dicha solución conduce a una situación de incertidumbre en el ordenamiento jurídico italiano, respecto a la determinación del régimen de prescripción aplicable, que menoscaba el principio de precisión de la ley aplicable. Además, asume que debido a la inaplicación de las normas italianas sobre prescripción, podrían imponerse a las personas afectadas sanciones que, con toda probabilidad, habrían evitado si se hubieran aplicado las mencionadas disposiciones, por lo que podrían quedar sujetas retroactivamente a condiciones de exigencia de responsabilidad penal más severas que las vigentes en el momento de la comisión de la infracción, siendo ello incompatible con el principio de legalidad penal. Sobre la base de estas dos constataciones, el TJUE establece una limitación a los efectos de la primacía afirmando que «si el juez nacional considera que la obligación de no aplicar las disposiciones del Código penal controvertidas vulnera el principio de legalidad de los delitos y las penas, no debería cumplir dicha obligación y ello aunque su respeto permitiera subsanar una situación nacional opuesta al derecho de la Unión. Corresponde por tanto al legislador nacional adoptar las medidas necesarias» ${ }^{79}$.

La sentencia M.A.S. y M.B. es histórica porque es la primera vez que el TJUE admite un límite externo a los efectos de la primacía de las normas de la UE. En concreto, el juez nacional no tendrá que inaplicar la norma nacional contraria a una norma de la UE si con ello infringe un derecho fundamental protegido por su constitución nacional. El efecto de exclusión de la primacía y, en su caso, su efecto de sustitución ceden al entrar en conflicto con un derecho fundamental. Esta limitación de la primacía está conectada con los límites internos a este principio que el TJUE ha aceptado en su jurisprudencia y analizados en el epígrafe anterior. Por ello, el TJUE se apoya para establecer este límite externo en la aplicación, por analogía, de la sentencia Impresa Pizzarotti, que establece el límite interno del principio de cosa juzgada.

El límite externo al principio de primacía establecido por la sentencia M.A.S. y M.B. supone, en definitiva, que el juez nacional no tiene que activar los efectos de la primacía de la norma de la UE cuando estos den lugar a una situación de violación de un derecho fundamental protegido por el derecho interno de un Estado miembro.

Puede que la sentencia M.A.S. y M. B. no sea un pronunciamiento aislado, ya que la reciente sentencia Dzivev aplica, también, la protección de derechos fundamentales como límite (interno) a la operatividad de los efectos de la primacía. En ella, el TJUE afirma que

79 Ibid., apdos. 59-61. 
la obligación de garantizar la recaudación eficaz de los recursos de la Unión no exime a los órganos jurisdiccionales nacionales del necesario respeto de los derechos fundamentales garantizados por la Carta y los principios generales del derecho de la Unión, dado que los procedimientos penales incoados por infracciones en materia de IVA constituyen una aplicación del derecho de la Unión, en el sentido del artículo 51, apartado 1, de la Carta. En el ámbito penal, estos derechos y principios generales deben ser respetados no solo en los procedimientos penales, sino también durante la fase de la investigación preliminar, desde el momento en que se acuse a la persona de que se trata ${ }^{80}$.

En este asunto, se trataba de la inaplicación de una norma búlgara que obligaba al juez nacional a descartar del procedimiento penal medios de prueba, como las interceptaciones de las telecomunicaciones, que requieren una autorización judicial previa cuando dicha autorización ha sido emitida por una autoridad jurisdiccional sin competencia para ello. Las interceptaciones de las telecomunicaciones constituyen una injerencia en el derecho a la vida privada, consagrado en el art. 7 de la Carta, que, con arreglo al art. 52, apdo. 1, de la Carta, solo puede admitirse si está prevista por la ley y cuando, siempre que se respete el contenido esencial de dicho derecho y el principio de proporcionalidad, es necesaria y responde efectivamente a objetivos de interés general reconocidos por la Unión ${ }^{81}$. Por ello, el TJUE concluye que el derecho de la UE no puede obligar al juez nacional a inaplicar dicha norma búlgara de procedimiento, ni aun cuando la utilización de pruebas obtenidas ilegalmente pudiera incrementar la eficiencia de los procedimientos penales que permiten a las autoridades nacionales sancionar en determinados casos el incumplimiento del derecho de la Unión. No operan los efectos de la primacía del art. 325 TFUE respecto a una norma procesal búlgara que dificulta su aplicación, porque la inaplicación de dicha norma nacional violaría la protección del derecho a la vida privada. En este caso, la sentencia Dzivev no deja claro si se trata de un límite externo o interno a la primacía, aunque más parece interno, ya que el razonamiento del TJUE se funda en los arts. 7 y 52 de la Carta.

La sentencia M.A.S. y M.B. y el límite externo que acepta al principio de primacía han sido objeto de valoraciones tremendamente dispares. Algunos comentaristas (Burchardt, 2017) consideran que esta sentencia asesta una

80 Sentencia de 17 de enero de 2019, Dzivev y otros, C-310/16, EU:C:2019:30, apdo. 33, y sentencias de 5 de diciembre de 2017, M.A.S. y M.B., C-42/17, EU:C:2017:936, apdo. 52, y de 5 de junio de 2018, Kolev y otros, C-612/15, EU:C:2018:392, apdos. 68 y 71 .

81 Sentencia de 17 de diciembre de 2015, WebMindLicenses, C-419/14, EU:C:2015:832, apdos. 71 y 73 . 
estocada mortal al principio de primacía tal como ha sido definido en la jurisprudencia clásica del TJUE desde la sentencia Costa/ENEL. Otros entienden que esta sentencia precisa la aplicación del principio de primacía en un supuesto específico en el que su aplicación provoca una violación del principio de legalidad penal de la constitución de un Estado miembro. Ante esta situación, el TJUE flexibiliza los efectos de la primacía (Claes, 2015) aceptando un límite externo en la misma línea seguida para la admisión de los límites internos a dicha primacía (Rauchegger, 2018: 1536). Por último, varios comentaristas (Dubout, 2018; Sarmiento, 2018b) hacen una lectura de la sentencia M.A.S. y M.B. en el contexto del diálogo entre el TJUE y los tribunales constitucionales y supremos nacionales, valorando que el TJUE haya sabido reaccionar y aportar una solución pragmática al conflicto frontal entre el derecho de la UE (tras la sentencia Taricco) y el principio de legalidad penal del art. 25 de la Constitución italiana, suscitado por el Tribunal Constitucional italiano.

En cualquier caso, la sentencia del TJUE ha conseguido desactivar el grave conflicto "constitucional» que para el derecho de la UE suponía el asunto M.A.S. y M.B., ya que la Corte Costituzionale italiana no activó los contralímites y en su sentencia de 10 de abril de $2018^{82}$ ha afirmado la inaplicabilidad de la «regla Taricco» sobre el cálculo de la prescripción para los delitos en materia IVA.

\section{REFLEXIONES FINALES}

La primacía, junto con el efecto directo, han sido los dos principios fundamentales sobre los que el TJUE ha articulado las relaciones entre el derecho de la UE y los derechos internos. Con ellos ha afirmado la autonomía y la especificidad del derecho de la Unión respecto a los derechos nacionales y en relación con el derecho internacional, a la vez que ha garantizado la uniformidad y la efectividad necesarias para que las normas de la UE se apliquen adecuadamente en los derechos internos de sus Estados miembros.

La primacía ha sido configurada por el TJUE en su jurisprudencia clásica como un principio incondicional y absoluto, cuya aplicación ha recaído fundamentalmente sobre las espaldas de los jueces nacionales como jueces ordinarios de la aplicación del derecho de la UE. Esta primacía opera mediante un efecto de exclusión, según el cual el juez nacional (y las administraciones nacionales) debe dejar inaplicada la norma interna contraria a una norma de la UE en el litigio del que conoce, y mediante un efecto de sustitución, en

82 Sentencia 115/2018, IT:COST:2018:115. 
virtud del cual el juez nacional inaplica la norma nacional incompatible y resuelve el litigio utilizando la norma de la UE. En principio, el efecto de exclusión de la primacía debe operar siempre que haya conflicto entre una norma interna y una norma de la UE. El efecto de sustitución solo será factible cuando la norma de la UE tenga efecto directo, es decir, sea lo suficientemente clara, precisa e incondicional como para que el juez pueda resolver el litigio haciendo uso de ella.

En su jurisprudencia más reciente, el TJUE ha afinado la primacía reforzando sus contornos, pero también se ha visto «obligado» a admitir, primero, límites internos a la aplicación del principio de primacía y, posteriormente, un límite externo.

La restricción por el principio de cosa juzgada y la suspensión temporal de la operatividad de la primacía para evitar un vacío normativo me parecen límites internos a la operatividad de la primacía totalmente razonables, porque en ellos subyace la idea de garantizar la seguridad jurídica ${ }^{83}$ y la estabilidad de las resoluciones judiciales. Nada que objetar al respecto.

Por el contrario, el límite interno a la primacía extraído de la ausencia de efecto directo de normas de la UE creo que no ha sido adecuadamente configurado por el TJUE en sus sentencias sobre la ausencia de obligación del juez nacional de inaplicar normas internas contrarias a directivas invocadas en relaciones horizontales (sentencias Fenoll y Smith). En estos casos, el juez nacional va a aplicar una norma nacional contraria a la disposición de una directiva de la UE, salvo que el contenido de esa directiva se refleje en un derecho protegido por la Carta de Derechos Fundamentales o en un principio general del derecho de la UE (sentencias Engerberg, Bauer y Willmeroth, IR y Cresco Investigation). En el caso de las decisiones marco, la situación con la jurisprudencia Poplawski II es aún más discutible, ya que la falta de efecto directo de la decisión marco, tanto en relaciones horizontales como verticales, conlleva que el juez nacional no tiene la obligación de dar efectividad a la primacía y excluir la aplicación de las disposiciones de su derecho interno incompatibles con el derecho de la Unión. Esta jurisprudencia impide la aplicación uniforme y efectiva de una decisión marco.

El sacrificio de la primacía ante la ausencia de efecto directo de una norma me parece discutible y creo que no se puede afirmar de manera general, como lo ha hecho el TJUE en su reciente jurisprudencia. Una adecuada distinción del efecto de exclusión y del efecto de sustitución de la primacía habría permitido salvar siempre su efecto de exclusión y sacrificar solo su efec-

83 Sobre el principio de seguridad jurídica, me remito al análisis de Martín Rodríguez (2016). 
to de sustitución en caso de normas carentes de todo tipo de efecto directo, como las decisiones marco, o de normas sin efecto directo horizontal, como las directivas. En el asunto Poplawski, como he señalado, esta solución habría llevado a inaplicar la norma neerlandesa que preveía una causa de inejecución facultativa de una ODE, regulada de forma contraria a la decisión marco, y a resolver el litigio de acuerdo con las otras normas del derecho neerlandés sobre la ODE, compatibles con dicha decisión marco. Habrá que estar atentos a la evolución de esta jurisprudencia del TJUE que sacrifica la primacía ante el efecto directo, ya que algunos abogados generales han defendido opiniones divergentes a las de las sentencias del TJUE.

Por último, en lo que respecta al límite externo a la primacía establecido en la sentencia M.A.S. y M.B., no resulta fácil hacer una valoración precisa. Está claro que el TJUE flexibiliza la aplicación de la primacía ante un conflicto de su jurisprudencia Taricco con el principio de legalidad penal de la Constitución italiana y frente a una posición de fuerza, pero a la vez colaborativa, de la Corte Costituzionale. Esta flexibilización es pilotada por el propio TJUE, sin referirse para nada a los contralímites a la primacía del derecho de la UE suscitados por el Tribunal Constitucional italiano, e indicando que la sentencia Taricco fue pronunciada sin que el juez italiano del litigio principal informara al TJUE adecuadamente de la articulación de la prescripción como un elemento material del principio de legalidad en la Constitución italiana. La vía elegida por el TJUE es admitir un límite externo a la primacía, que consiste en levantar la obligación del juez nacional de inaplicar la norma nacional contraria al derecho de la UE si dicha inaplicación vulnera un derecho fundamental como el principio de legalidad penal, que se consagra en el art. 25 de la Constitución italiana y que también protege el art. 49 de la Carta. Este límite externo a la primacía lo conecta el TJUE, además, por analogía con los límites internos y en especial, con el resultante del principio de cosa juzgada.

No creo que el límite establecido por la sentencia M.A.S. y M.B. sea el principio del fin de la primacía, ni tampoco que este pronunciamiento abra el camino a un pluralismo constitucional en el que el nivel de protección de los derechos fundamentales sea fijado por el TJUE con una colaboración más estrecha con los tribunales constitucionales nacionales de la que ha habido hasta ahora. Posiblemente, la sentencia M.A.S. y M.B. sea una solución pragmática del TJUE a un conflicto agudo entre el derecho de la UE y el derecho constitucional de un Estado miembro, que flexibiliza la primacía del derecho de la UE para que sus efectos no provoquen unas consecuencias indeseables desde el punto de vista de la protección de los derechos fundamentales.

El derecho de la UE sin la primacía perdería su principal seña de identidad y el TJUE debe velar siempre por preservarla. No obstante, la utilización de una cierta flexibilidad parece necesaria en determinados casos, con objeto 
de que los efectos de la primacía no generen resultados incompatibles con la seguridad jurídica o con la protección de derechos fundamentales. Entiendo que los límites a la primacía que ha aceptado el TJUE obedecen a esta lógica.

\section{Bibliografía}

Amalfitano, C. (2018). La vicenda Taricco e il dialogo (?) tra giudici nazionali e Corte di giustizia. Il Diritto dell'Unione Europea, 1, 153-202.

Arena, A. (2019). Sul carattere «assoluto» del primato del diritto dell'Unione europea. Studi Sullintegrazione Europea, 3, 317-340.

Bin, R. (2017). Taricco: aspettando Godot, leggiamo Yves Bot. Forumcostituzionale. it, 1-4. Disponible en: https://bit.ly/2JXirp6.

Burchardt, D. (2017). Belittling the Primacy of EU Law in Taricco II. VerfBlog, 7 de diciembre de 2017.

Claes, M. (2015). The Primacy of EU Law in European and National Law. En A. Arnull y D. Chalmers (eds.). The Oxford Handbook of European Law (pp. 178-211). Oxford: Oxford University Press.

Dougan, M. (2007). When worlds collide! Competing visions of the relationship between direct effect and supremacy. Common Market Law Review, 44 (4), 931-963.

Dubos, O. (2003). L'invocabilité d'exclusion des directives: une autonomie enfin conquise. Revue Française de Droit Administratif, 2003, 200-220.

Dubout, E. (2018). La primauté du droit de l'Union et le passage au pluralisme constitutionnel. Revue Trimestrielle de Droit Européen, 3, 563.

Faggiani, V. (2018). El diálogo jurisdiccional tras la sentencia del TJUE M. A. S. y M. B.: entre estándar europeo de protección y tendencias centrípetas. Revista de Derecho Comunitario Europeo, 60, 639-676. Disponible en: https://doi. org/10.18042/cepc/rdce.60.05.

López Escudero, M. (2019). El juez nacional como juez de la Unión y la aplicación del derecho de la UE en los derechos internos. En J. I. Signes de Mesa (dir.). Derecho Procesal Europeo (pp. 69-101). Madrid: Iustel.

Martín Rodríguez, P. (2007). Res judicata pro veritate habetur c. primacía del Derecho comunitario: ¿un combate por librar? Revista Española de Derecho Europeo, 24, 521-557.

Martín Rodríguez, P. (2016). The principle of legal certainty and the limits to the applicability of EU law. Cahiers Droit Européen, 1, 115-140.

Perlo, N. (2017). L'affaire Taricco: la voie italienne pour préserver la collaboration des juges dans l'Union européenne. Revue Trimestrielle de Droit Européen, 3, 739.

Rauchegger, C. (2018). National constitutional rights and the primacy of EU law: M.A.S. Common Market Law Review, 55, 1521-1547. 
Rodríguez Iglesias, G. C. y López Escudero, A. (2010). El derecho de la Unión Europea. En M. Díez de Velasco (ed.). Las organizaciones internacionales (pp. 695-725). Madrid: Tecnos.

Rodríguez Iglesias, G. C. y Valle Gálvez, A. (1997). El Derecho Comunitario y las relaciones entre el Tribunal de Justicia de las Comunidades Europeas, el Tribunal Europeo de Derechos Humanos y los Tribunales Constitucionales Nacionales. Revista de Derecho Comunitario Europeo, 2, 329-376.

Sarmiento, D. (2018a). El Derecho de la Unión Europea. Madrid: Marcial Pons.

Sarmiento, D. (2018b). Adults in the (Deliberation) Room. A comment on M.A.S. Quaderni Costituzionali, 1, 225-231.

Simon, D. (1997). La directive européenne. Paris: Dalloz.

Simon, D. (2010). L'invocabilité des directives dans les litiges horizontaux: confirmation ou infléchissement? Revue Europe, 3, 1.

Sowery, K. (2017). Reconciling primacy and environmental protection: Association France Nature Environnement. Common Market Law Review, 54, 1157-1178.

Turmo, A. (2019). La efectividad del Derecho de la Unión europea como motivo de protección de la cosa juzgada nacional: nota sobre la sentencia de 24 de octubre de 2018 XC y otros. Revista de Derecho Comunitario Europeo, 64, 599-626. Disponible en: https://doi.org/10.18042/cepc/rdce.63.07.

Wildemeersch, J. (2018). Primauté, vous avez dit primauté? Sur l'invocabilité des directives dans les litiges entre particuliers. Revue des Affaires Européennes, 3, 541-553. 